\title{
Research Paper \\ The Compare the effect of action video games and fundamental sports games on the Enjoyment of physical activity in Fourth grade elementary students
}

\author{
Mostafa Taheri Nasab ${ }^{1}$, Marzieh Balali ${ }^{2}$, Sadegh Nasri ${ }^{3}$ \\ 1. Ph.D Student in Motor Behavior, Faculty of Physical Education and Sport Sciences, Central Tehran Branch, Islamic Azad \\ University, Tehran, Iran. \\ 2. Assistant Professor, Department of Motor Behavior, Faculty of Physical Education and Sport Sciences, Central Tehran Branch, \\ Islamic Azad University, Tehran, Iran. \\ 3. Associate Professor, Department of Educational Sciences and Psychology, Faculty of Psychology, Tarbiat Dabir Shahid Rajaei \\ University, Tehran, Iran.
}

Citation: Taheri Nasab M, Balali M, Nasri S. The Compare the effect of action video games and fundamental sports games on the Enjoyment of physical activity in Fourth grade elementary students. J of Psychological Science. 2022; 20(107): 2077-2093.

URL: https://psychologicalscience.ir/article-1-1429-fa.html
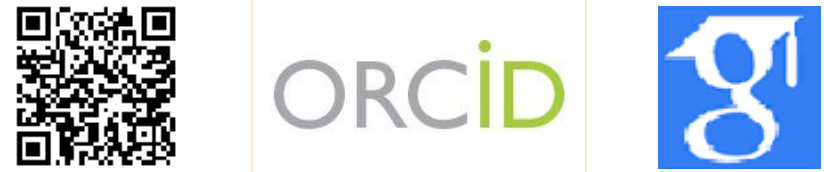

$\underline{10.52547 / J P S .20 .107 .2077}$

A R T I C L E I N F O

A B S T R A C T

Keywords:

Action video game, fundamental sports game, enjoyment of physical activity,

students

Received: 30 Sep 2021 Accepted: 30 Oct 2021 Available: 21 Jan 2022
Background: Studies have shown that games based on fundamental motor skills and action video are effective in acquiring motor skills. However, studies on the Enjoyment factor of physical activity as an important psychological factor are rare.

Aims: The aim of this study was to compare the effectiveness of active video games and fundamental sports games on the enjoyment of physical activity in fourth grade elementary school male students. Methods: The research was quasi-experimental with pre-test and post-test design. The statistical population included all 10 years Children in Ahvaz. 60 Children were selected by available sampling method and randomly divided into 3 groups of 30 individual. The research instruments included the Xbox 360 Kinect and Moore enjoyment questionnaire (2009). Analysis of covariance with bonferroni were used to analyze the data.

Results: fundamental sports and action video games had a significant effect $(p<.05)$ on children's enjoyment of physical activity. Also, there was no difference between the fundamental sports and action video in the factor of enjoyment of physical activity. So that the larger perceived group was more associated with alpha wave reduction.

Conclusion: Based on the findings of this study, it is possible to use both fundamental sports and Action video methods, or a combination of both methods in the absence of suitable environmental conditions for increase enjoyment.

* Corresponding Author: Marzieh Balali, Assistant Professor, Department of Motor Behavior, Faculty of Physical Education and Sport Sciences, Central Tehran Branch, Islamic Azad University, Tehran, Iran.

E-mail: balalimarzie@gmail.com

Tel: (+98) 9375025639

2476-5740/ (C) 2021 The Authors. This is an open access article under the CC BY-NC-ND license

(https://creativecommons.org/licenses/by-nc/4.0/). 


\section{Extended Abstract}

\section{Introduction}

The researchers of children's sports indicated that enjoyment and recreation are the main factors for beginning and retaining participation in sports and presented it as the main predictor of sports commitment (Weiss et al., 2002). Increasing the enjoyment of physical activity can enhance participation in physical activity among children and adults and create positive health outcomes throughout life (Barnett et al., 2019). Understanding the sources of enjoyment is significant since it can provide effective experiences for children and enhance their level of physical activity. According to Garvey (1990), game is one of the enjoyable activities for children to play and enjoy. Researchers have recently studied the games which are based on basic motor skills or sport-based games. The games based on basic motor skills are the basic motor skills which children learn through games and practice (Bremer and Lloyd, 2016). Nevertheless, the results of studios on the effects of games on enjoyment are slight. For example, Ghari et al. (2021) indicated that a sportbased educational approach can enhance the level of physical activity and enjoyment of physical activity among students. In another study, Filanowski et al. (2021) revealed that the enjoyment of physical activity can increase by participating in games. Another category of games is related to virtual reality. Such games are called video games and have a new class of games. These types of games enable the body to control the game and require great motor skills. Studies in this field indicated that these games can be effective in increasing the enjoyment of physical activity (Jelsma et al., 2015, Smith Engelsman et al., 2016). The above-mentioned studies reported the separate effects of each game on enjoyment while the results of comparative studies in this field were ignored. Thus, since the enjoyment of physical activity is the main factor in participating in physical activity and the games based on basic motor skills in this study are a new designed approach, and also since apartment living has become highly prevalent in the communities, this study aimed to evaluate whether an alternative approach called active video can be introduced in case of inappropriate environmental conditions. Since there is no comparative study in this field, this study sought to compare the effect of sportbased games and active video games on the enjoyment of physical activity among students.

\section{Method}

The method of this study was quasi-experimental while its design was pre-test and post-test. The sample included 60 available children at the age 10 years in three groups of active video, sport-based games, and control. The tool used in this study was an Xbox 360 Kinect device for video games conditions. In addition, the Moore questionnaire (2009) was used to measure the enjoyment of physical activity among children. This single factor questionnaire has 12 questions and has a five-point Likert scale. The reliability of this questionnaire was 0.87 and its time reliability was 0.83 . In this study, first the participants filled the Moore questionnaire. Then, the sport-based games group performed the intervention of basic game in eight weeks, twice a week, and 20 minutes per session. Furthermore, the active video group practiced with the related device exactly as much as the sport-based games group. At the end of the training sessions, the subjects re-filled the Moore Physical Activity Enjoyment Questionnaire. Eventually, the covariance analysis and Bonferroni post hoc test were used to analyze the data.

Table 1. Results of analysis of covariance for physical activity enjoyment scale

\begin{tabular}{ccccccc}
\hline Source of changes & Total squares & df & Average squares & F & SIG & Squared Eta \\
\hline Assumption of homogeneity slope homogeneity & 27.85 & 2 & 13.92 & 2.44 & 0.09 & 0.085 \\
Pretest & 6178.61 & 1 & 6178.61 & 1053.89 & $0.001 *$ & 0.950 \\
Group & 1309.49 & 2 & 654.71 & 111.51 & $0.001 *$ & 0.799 \\
Error & 1066.67 & 56 & 19.04 & $\ldots \ldots$. & $\ldots \ldots \ldots$ & $\ldots \ldots \ldots$ \\
\hline
\end{tabular}




\section{Monthly Journal of Psychological Science}

\section{Results}

Covariance analysis (before and after training) was used for comparing the effect of active video games and sport-based games on the enjoyment of physical activity. The results of this section are summarized in Table 1. As shown, the regression slope homogeneity assumption was first tested to confirm the main assumption of the analysis of covariance. The results indicated that the interaction between the independent variable and the covariate variable $(\mathrm{F}=2.44$, sig $=$ $0.09, \eta^{2}=0.085$ ) was not significant; Thus, the regression homogeneity regression assumption was observed. Due to the confirmation of homogeneity in the regression slope in the ANCOVA test, this study evaluated the effect of active video games and sportbased games on the enjoyment of physical activity. The results of ANCOVA test indicated that active video games and sport-based games have a significant effect on the enjoyment of physical activity $\left(\mathrm{F}=111.51\right.$, sig $\left.=0.001, \eta^{2}=0.799\right)$. In addition, the results related to the difference between the groups ( $F$ $=111.51$, sig $=0.001, \eta^{2}=0.799$, ) revealed a significant difference between the research groups while the active video games and game-basic sports groups had a greater increase in the enjoyment of physical activity from pre-test to post-test compared to the control group. Further, a significant difference was observed between the active video games group with the control $(\mathrm{P}=0.001)$ and the sport-based games with the control $(\mathrm{P}=0.001)$. However, no significant difference was found in terms of enjoyment between these active video games and sports-based games. In addition, both experimental groups had led to an improvement in the enjoyment scale at the same extent.

\section{Conclusion}

The results of this study indicated a significant difference between the sport-based and active video groups, as well as the control group in terms of the enjoyment of physical activity. The results of this study were in favor of active video and sports-based groups. The results of this study are consistent with the findings of Flenowski et al. (2021) Bryant et al. (2015), Lamel et al. (2016) in the difference between the sport-based and control groups. In interpreting this superiority, two critical reasons can be mentioned
Vol. 20, No. 107, Winter(February) 2022

including entertainment and physiological changes. In terms of entertainment, the studies indicated that participating in physical activity in any form of game leads to an increased enjoyment and entertainment (Shojaei and Daneshfar, 2018). In the second case, some studies indicated that along with game and physical activity, the level of neurotransmitters, especially dopamine and monamine changes significantly and such changes affect the child's emotional state spontaneously. The results on the difference between active video games and control group are consistent with the findings of Engelsman et al. (2016), Georg et al. (2016), Jelsma et al. (2015), Andrade (2020), and Pascoe et al. (2017). The findings of this section can be justified based on the theory of self-determination. In the theory of selfdetermination, there are three basic psychological needs such as self-determination, competence, and communication. This theory believes that the mentioned three fundamental needs are the basic foundations of human performance. On the other hand, individuals are constantly exposed to the experience of self-determination, competence, and communication in the environment. Based on this theory, active video games increase an enjoyment for activity because they lead to experiences of increasing motivation to participate in physical activity. Based on the increase, individuals feel selfusefulness and satisfaction with their performance and raise a sense of independence and selfdetermination. In case of no difference between active video games group and sport-based games, common neural mechanisms can be mentioned. Video game is a kind of observational learning and research indicated that an action observation network which is active in both real and video conditions. Maureen-Munst et al. (2016) reported that playing through observing videos such as playing in real conditions (sport-based) activates a common neural mechanism which is the primary motor cortex. According to Sabzevari et al. (2015), games and sports, practical experiences, and all types of challenging activities are the main source of learning. Game and sport are highly significant for improving the brain function. Activities such as running, jumping, hopping, and swimming which are among 
the basic sports skills strengthen the basal ganglia and corpus callosum. Sport and physical activity provide abundant oxygen to the brain and enhance the connection between neurons, resulting in the promotion and improvement of learning (Ghorbani and Qeysari, 2017). In addition, the study by Sabzevari et al. (2018), referred to cerebellar activity under real game conditions as reported by researchers in video game conditions (Andreiox and Proteo, 2016). Thus, the active video approach can be applied as an alternative for the times when there are no real conditions for practice.

\section{Ethical Considerations}

Compliance with ethical guidelines: This article is taken from the doctoral dissertation of the first author in the field of physical education and sports sciences in the Faculty of Physical Education, Islamic Azad University, Tehran Branch, with activity code 10121424972011 . Also, permits related to research in the statistical community have been issued by the Department of Educationof Ahvaz city.

Funding: This study was conducted as a $\mathrm{PhD}$ thesis with no financial support.

Authors' contribution: The first author was the senior author, the second were the supervisors and the third was the advisors. Conflict of interest: There is no conflict of interest in this study. Acknowledgments: I would like to appreciate the supervisor, the advisors, and Parents and children participating in the study. 


\section{مقايسه اثربخشى بازىهاى فعال ويدئويى و بازىهاى بايه ورزشى بر لذت از فعاليت بدنى در دانشآموزان مقطع جهارم ابتدايى}

\section{مصطفى طاهرىنسب'، مرضيه بلالى *'، صادق نصرى}

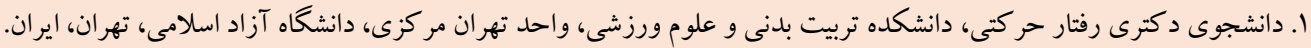

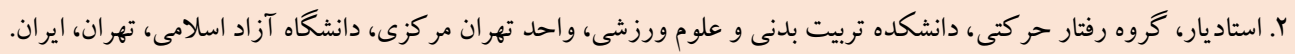

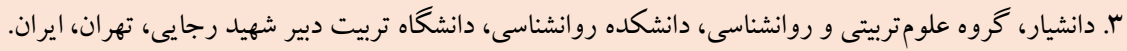

\begin{tabular}{|c|c|}
\hline جكيده & مشخصات مقاله \\
\hline زمينه: مطالعات نشان دادهاند كه بازىهاى مبتنى بر مهارتهاى حر كتى بايه و فعال ويدئويى بر كسب مهارتهاى حر كتى مؤثر مىباشد. با & 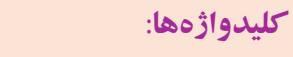 \\
\hline اين وجود مطالعات انجام شده در مورد فاكتور لذت از فعاليت بدنى به عنوان يكك عامل روانشناختى مهم نادر مىباشد. & بازى ويدئويى فعال، \\
\hline هدف: هدف از مطالعه حاضر مقايسه اثربخشى بازىهاى فعال ويدئويى و بازىهاى بايه ورزشى بر لذت از فعاليت بدنى در دانش آموزان & 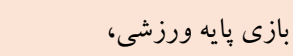 \\
\hline مٍر مقطع جهارم ابتدايى مىباشد. & 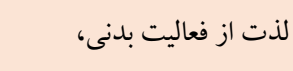 \\
\hline 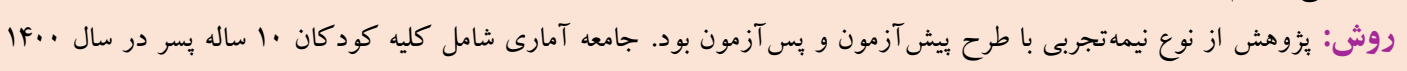 & دانش آموزان \\
\hline \multicolumn{2}{|l|}{ 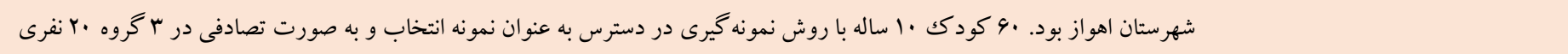 } \\
\hline \multicolumn{2}{|l|}{ 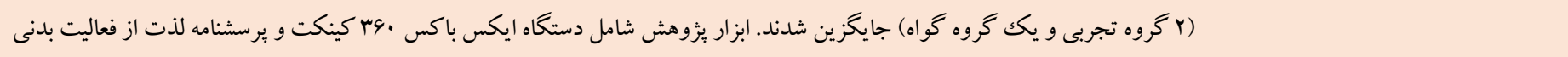 } \\
\hline \multicolumn{2}{|l|}{ مور (q. (Y) بود. از آزمونهاى آمارى تحليل كواريانس با تعقيبى بنفرونى جهت تحليل دادهها استفاده شد. } \\
\hline \multicolumn{2}{|l|}{ يافته ها: گروههاى بايه ورزشى و بازى ويدئويى فعال بر لذت از فعاليت بدنى كود كان تأثير معنادارى (ه./• >P) داشتند. همجنين بين گروه } \\
\hline هاى بايه ورزشى و ويدئويى فعال در فاكتور لذت از فعاليت بدنى تفاوتى مشاهده نشد. & 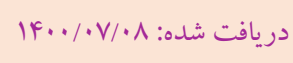 \\
\hline نتيجه كيرى: بر اساس يافتهاى اين تحقيق، مى توان از هر دو شيوه بايه ورزشى و ويدئويى فعال، يا تركيبى از هر دو شيوه در صورت فر اهم & 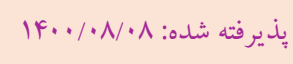 \\
\hline نبودن شرايط محيطى براى افزايش لذت بهره برد. & 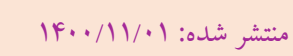 \\
\hline
\end{tabular}

* نويسنده مسئول: مرضيه بلالى، استاديار، گروه رفتار حر كتى، دانشكده ترييت بدنى و علوم ورزشى، واحد تهر ان مركزى، دانشكاه آزاد اسلامى، تهر ان، ايران. رايانامه: balalimarzie@gmail.com 
مختلفى كه از بازى وجود دارد مى توان زمينه لذت از فعاليت بدنى را در كود كان افزايش داد. يكى از مهمترين نوع بازى كه اخيرا مورد تحقيقات

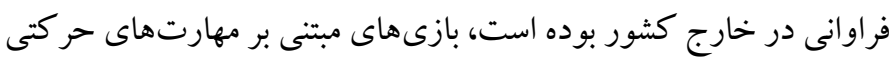

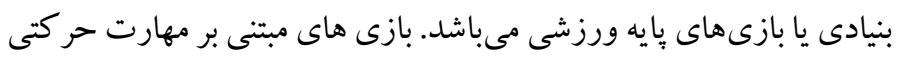

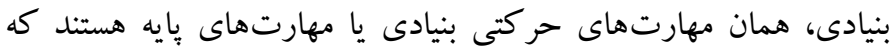

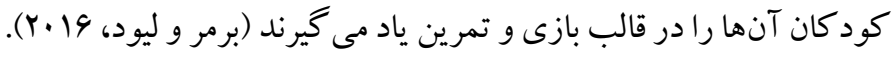

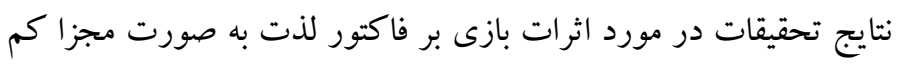

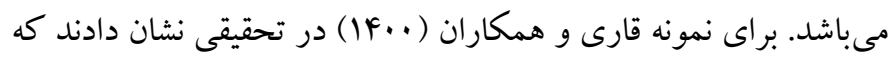

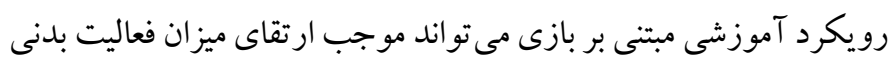

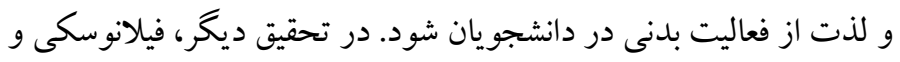
همكاران (Y.Y.Y) نشان دادند كه لذت از فعاليت بدنى و بازى مى تواند حاصل تعامل بين كودك و والدين باشد. بنابراين، آنها به بررسى تعامل

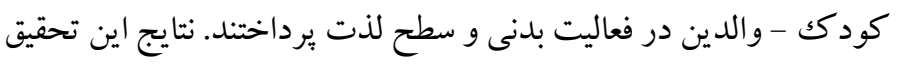
نشان داد كه فعاليت بدنى مشتركى كه بين كودكان و والدين وجود دارد، مى تواند سطح لذت دركك شده را هم در كود كان و هم در والدين افزايش دهد. بنابراين، اين تحقيق نشان داد كه فعاليت بدنى و بازى، به خصوص

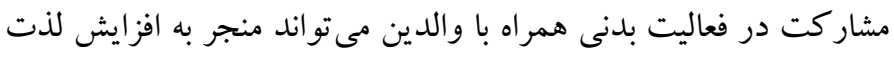
در فعاليت بدنى و بازى شده و به حفظ مشاركت حداكثر كود كان در

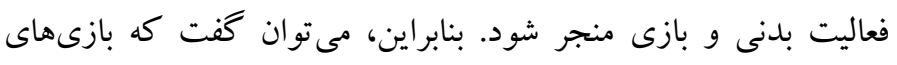

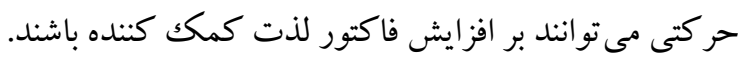
مطالب اشاره شده در بالا به شرايط بازى در محيط واقعى اشاره دارند.

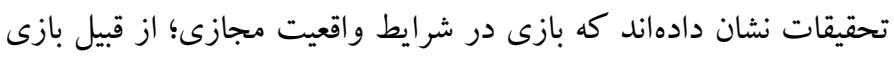

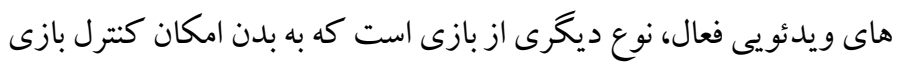
را مىدهد و همجينين نيازمند مهارت حركتى درشت مىباشد. در شرايط

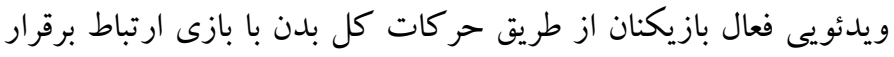

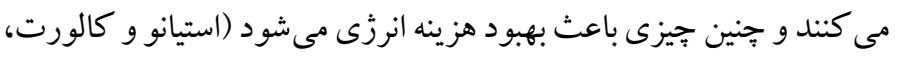

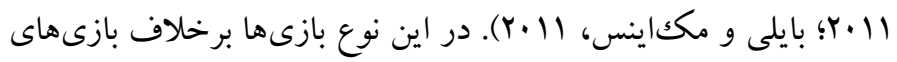

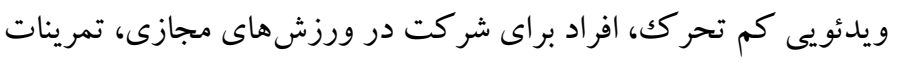
تناسب اندام يا ساير فعاليتهاى تعاملى را اجرا مى كنند. به طور بالقوه، اين

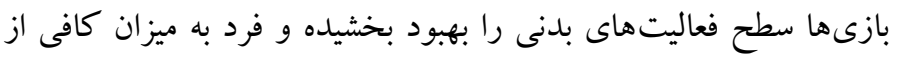
انرزى مصرفى دست مى يابد؛ همجِنين، خستخى حر كات مكرر بدنى را راز

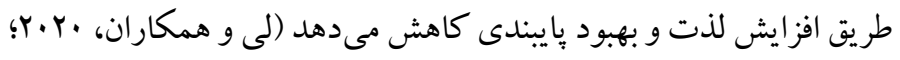

مقلفمه

لذت به عنوان يكك عامل اصلى براى ايجاد رفتارهاى انگگيزشى و بايدار در

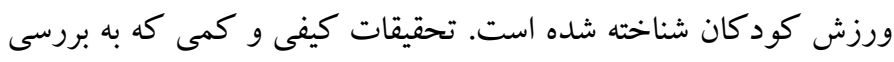

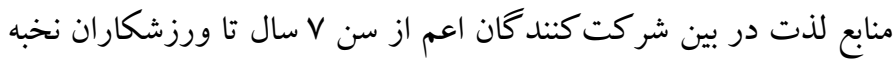

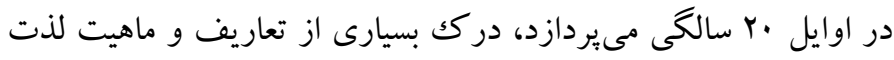

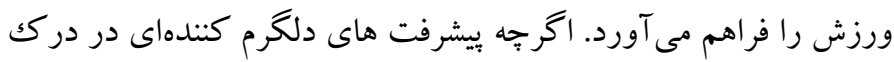
ساختار لذت در زمينهاى ورزش كود كان به وجود آمده است، اما دانش

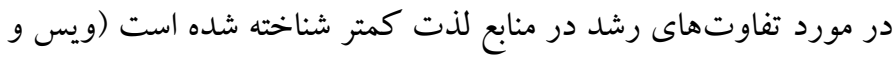

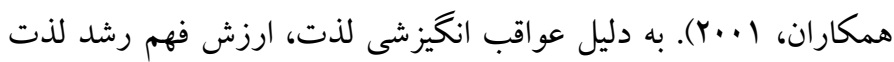
ورزشى ضرورى است. به طور خاص، محققان ورزش كود كان نشان داده

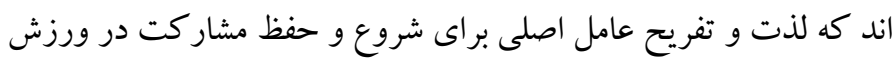

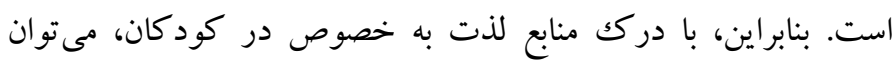

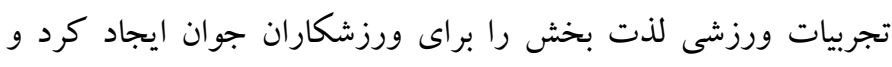

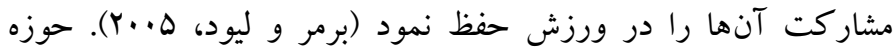
مطالعاتى جديدتر نشان دادهاند كه لذت با مشاركت در فعاليتهاى بدنى به طور مستقل در كود كان و بزر گسالان همراه مىباشد (كورتنيو همكاران،

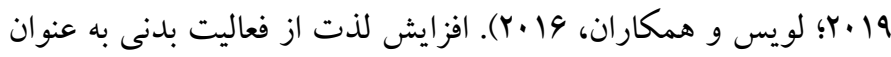

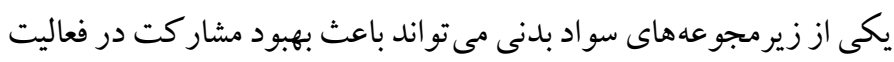
بدنى كود كان شده و به تبع آن منجر به بيامدهاى مثبت سلامتى در طول

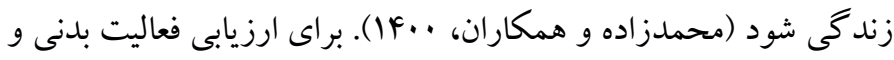
لذت براى كود كان در طى فعاليت بدنى، تحقيقات اضافى لازم است، كه به

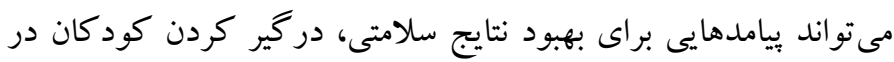

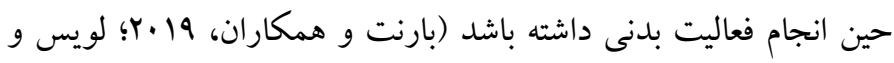

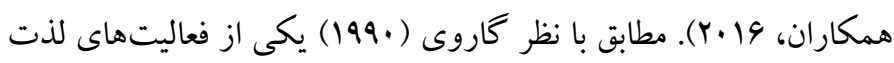
بخشى كه كود كان از طريق مشار كت در آن لذت برده و خشنود مى شوند

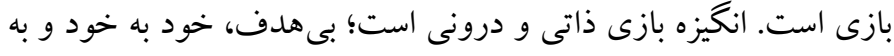

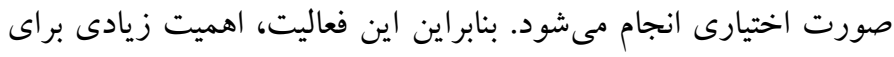

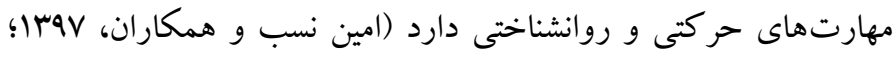

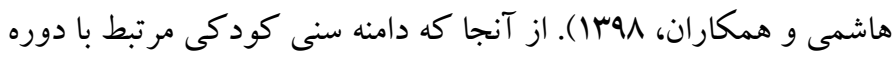
هاى حساس رشدى مىباشد، در صورت عدم فعاليت بدنى فرد دجار فقر تر حركتى مىشود؛ و اين شرايط مىتواند زمينه آسيب در هر دو حوزه حركتى و روانشناختى را ايجاد كند. خوشبختانه، به دليل دستهنيندىهاى 
و تأثيرات مثبت آنها در تحقيقات متعددى به اثبات رسيده است، بنابراين با وجود جنين جالش مثبت و منفى كه سر راه اين بازى ها وجود دارد، انجام تحقيقات در اين زمينه را ضرورى و حساس نشان مىدهد. همجنين، بازى

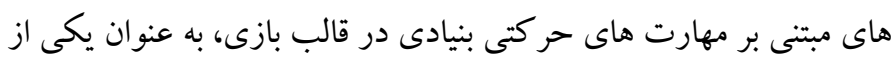
مهمترين مهارتهاى حركتى در دوران كودكى مىباشند، و موفقيت ورزشى آينده در فرصتهاى تمرينى كسب شده با توجه به اين مهارتها منعكس مى شود. دوران ابتدايى يكى از دوران كليدى بوده، و اين دوره مرهـ

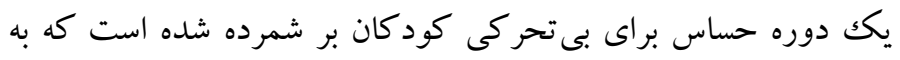

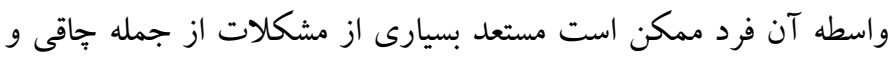
اضافه وزن و مشكلات روانى شود. دليل انتخاب بازى بايه اين است كه

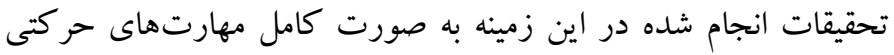
بنيادى را در قالب بازى طراحى نكردهاند. اما، در اين تحقيق مهارتهاى

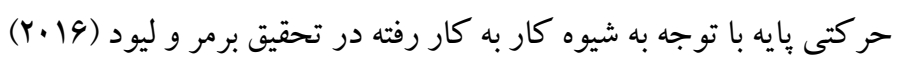

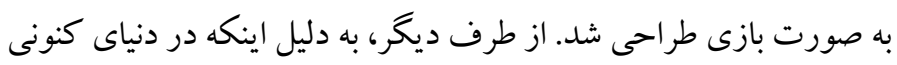

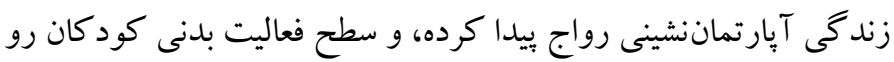
به كاهش مىباشد؛ و به تبع اين كاهش مشكلات جدى در ابعاد جسمانى و

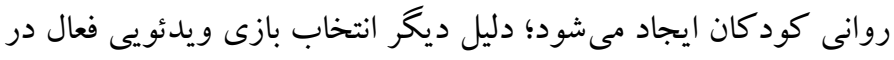

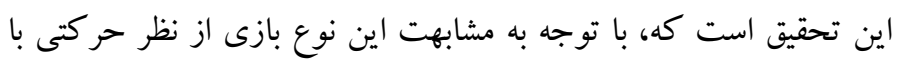

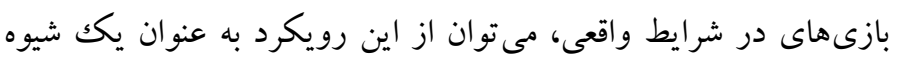

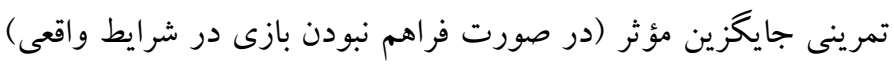

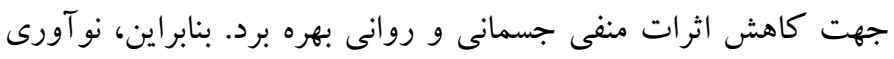
اصلى اين بثوهش در اين است كه در بي معرفى يكك رويكرد جايگزين

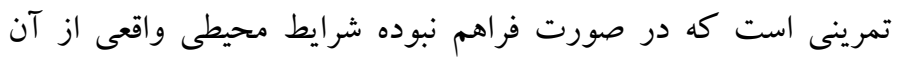

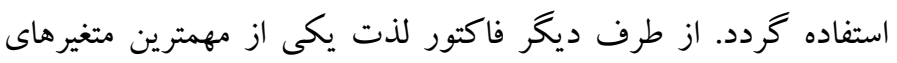
روانشناختى است كه منجر به افزايش مشار كت در فعاليت بلنى كود كان و

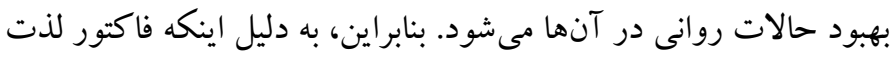

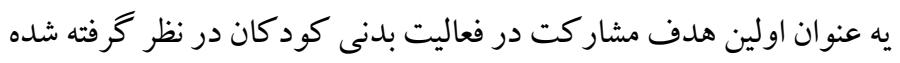
است و جنين متغيرى مى تو اند افراد را در هر دو حوزه روانى و بدنى در

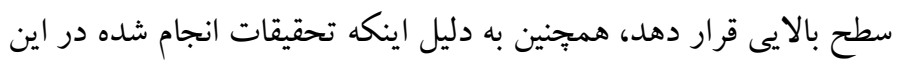
زمينه در داخل كشور به تا به حال اين فاكتور را به صورت مجزا بر روى

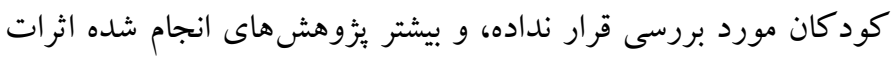

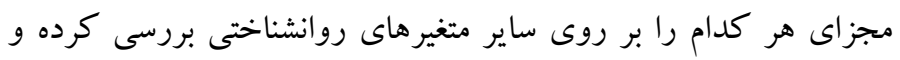

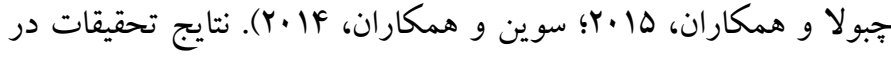
مورد بازىهاى ويدئويى و لذت نيز كم مىباشد. براى نمونه، جلسما و

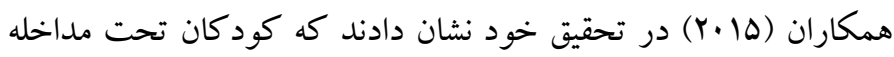

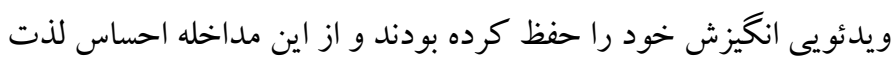
كردند. لذت يكى از خرده مقياس هاى انخيزش بوده كه در تحقيق جلسما

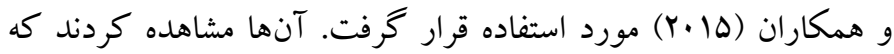

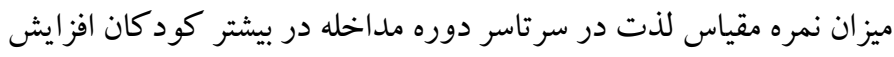

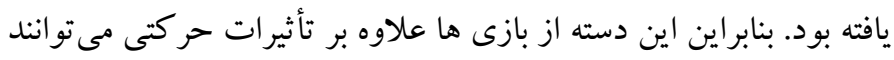

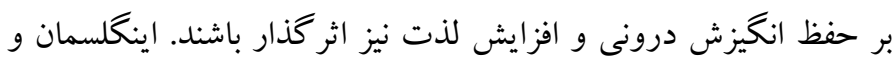
همكاران (Y.IV) نيز در تحقيق خود فاكتور لذت را مورد استفاده قرار دادند و نشان دادند كه ميزان لذت در سرتاسر مداخله حفظ شده بود و

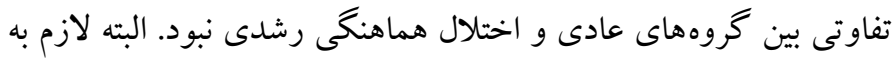
ذكر است كه ميزان تحقيقات در اين زمينه بسيار كم مىباشد.

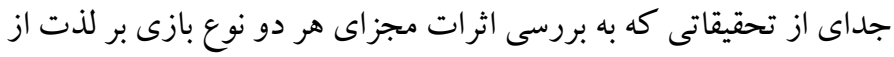

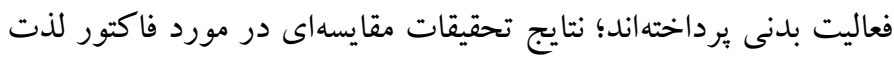
مغفول مانده است. بيشتر تحقيقات مقايسهاى به بررسى تفاوت بين هر دو

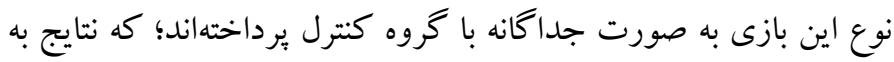

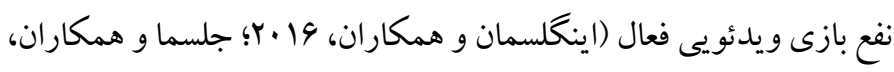

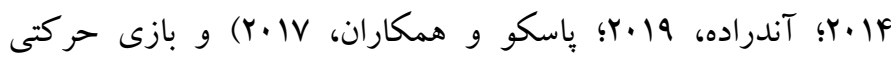

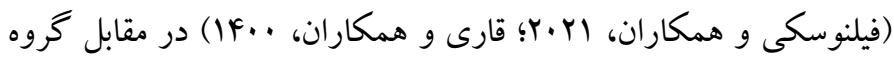
كنترل بوده است. اما تحقيقى كه نشان از مقايسه اثر بازىهاى بايه با هإِ ويدئويى فعال بر لذت از فعاليت بدنى باشد؛ تا به حال انجام نشده است.

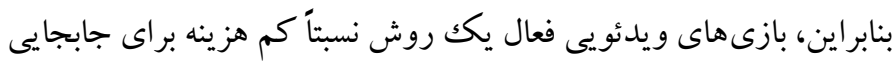

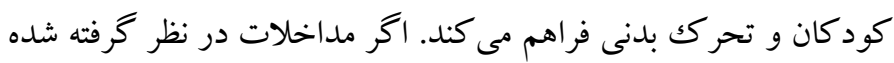

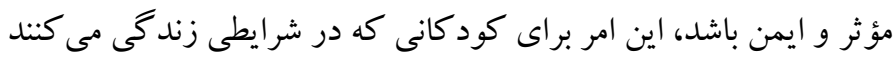
كه موانع زيست محيطى قابل توجهى براى مشاركت در آنها وجود دار دارد،

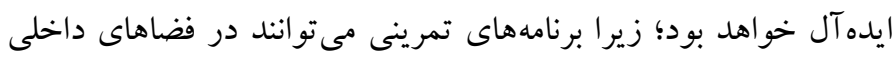

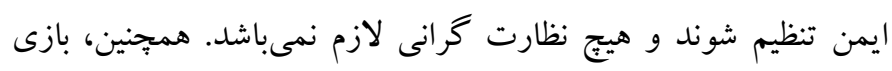

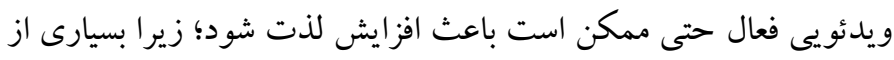

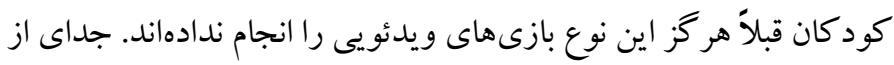

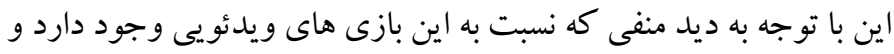

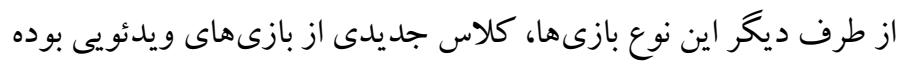


باكسهاى مجهز به كينكت، حر كات بدن رابه صورت آنى تحليل مى كنند

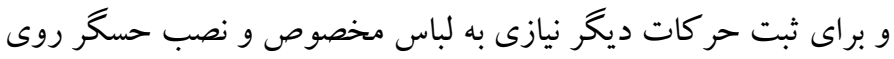

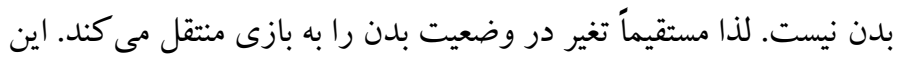

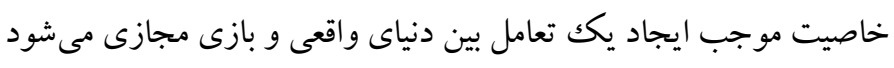
(كاستلو و وارنه، .Y.Y.). جداى از اين، براى ايجاد مداخله بازىهاى

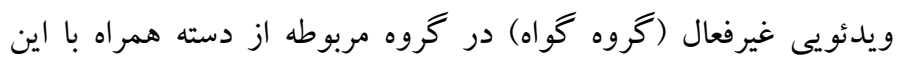
دستخاه (و بدون استفاده از كينكت) و بازىهاى غير كينكتى كه قابليت

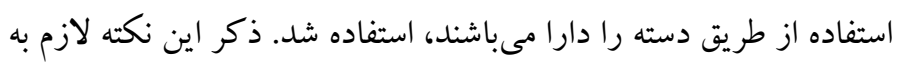
ذكر است كه دستخاههاى تجارى كه به صورت گسترده توسط كاربران استفاده مى شود و جواز مختلف توليد و كاربرد را دارا مىباشند، به نظر مى صى لهوري رسد نيازى به ارائه روايى و يايايى در تحقيقات نداشته باشند. در بسيارى از

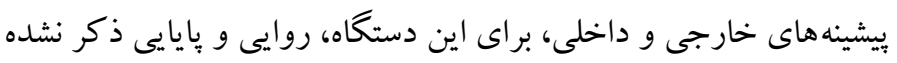

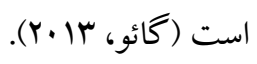

براى سنجش لذت از فعاليت بدنى از برسشنامه لذت مور استفاده شد. اين

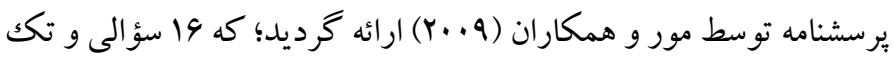
عاملى است. يرسشنامه مربوطه لذت فعاليت بدنى كود كان ب ا ساله و كمتر

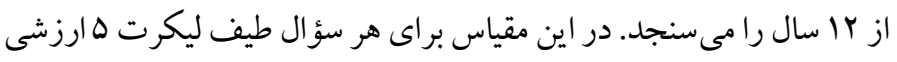

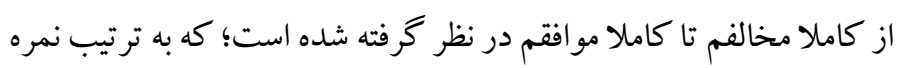
يكك تا ينج را به خود اختصاص مى دهند؛ هفت مورد از سؤالات (سؤالات

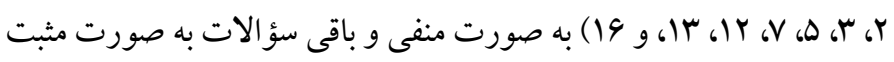

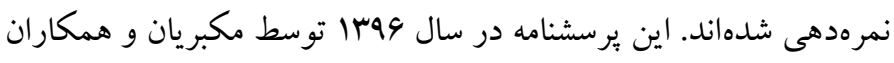

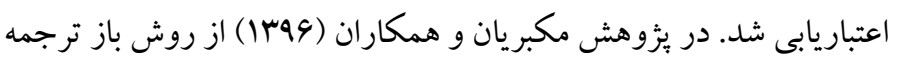
استفاده شد؛ سبس صحت ترجمه مقياس لذت فعاليت بدنى توسط سه

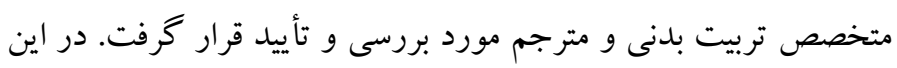

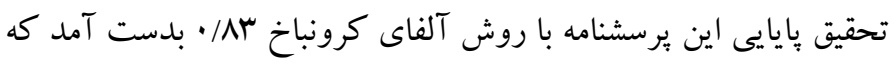

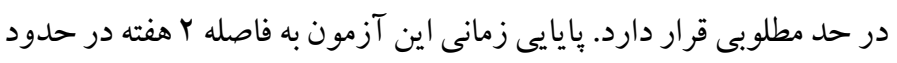

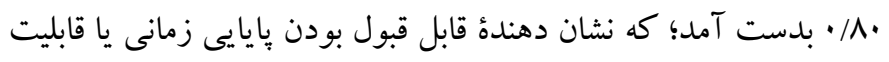

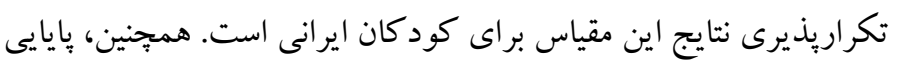

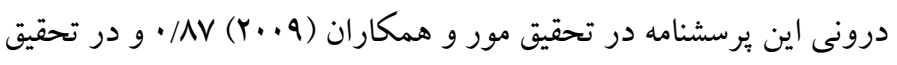

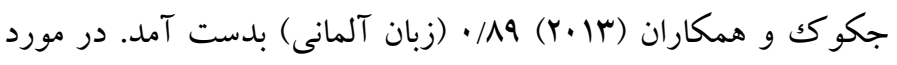

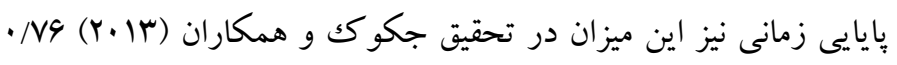

مقايسهاى بين اين دو شيوه گزارش نشده است، و در نهايت با توجه به

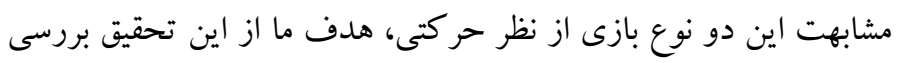

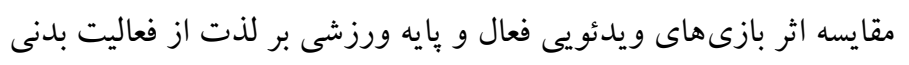
در دانش آموزان مقطع ابتدايى مىباشد.

\section{روش}

الف) طرح هئوهش و شركت كنند كان: يزوهش حاضر از نوع نيمه

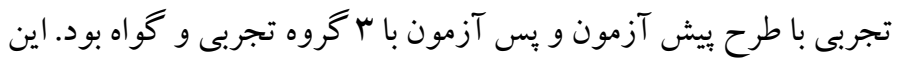

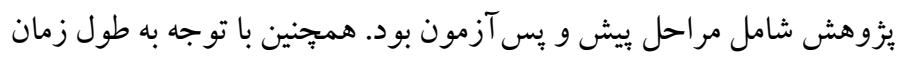

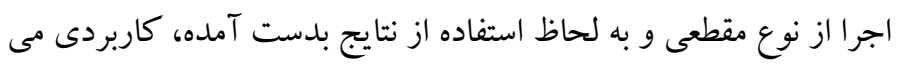

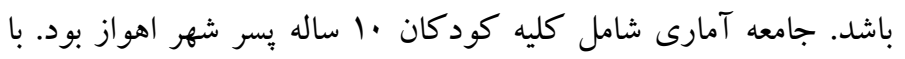

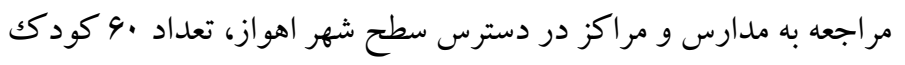

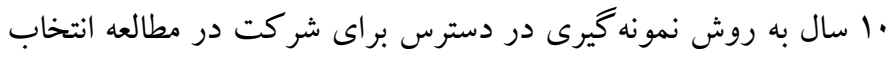

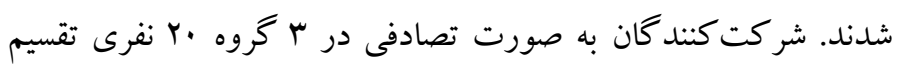
شدند (ץ گروه آزمايش، ا خروه كواه يا غير ويدئويى). كليه والدين شر كت كنند كان فرم رضايت شركت در بيزوهش را تكميل كردند. معيار

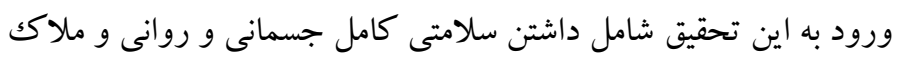

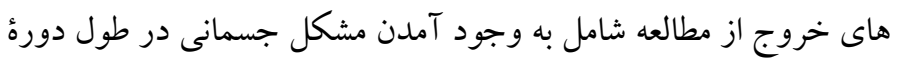
مداخله، عدم همكارى و حضور نامنظم در طى جلسات مداخله بود. لازم

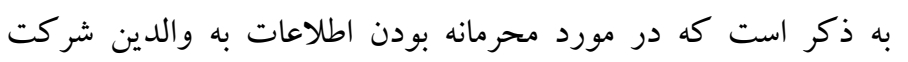
كنند كان و همجنين آزمودنىها اطمينان خاطر داده شد.

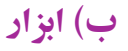
دستكاه ايكس باكس . وب كينكت با استفاده از اشعه مادون قرمز، الكويى

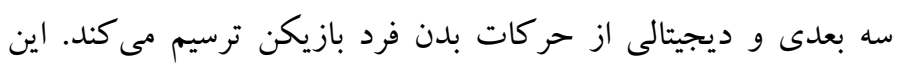

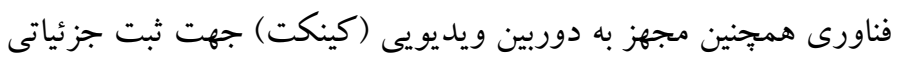

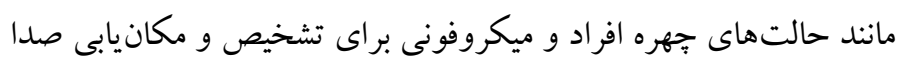

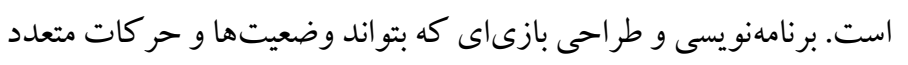

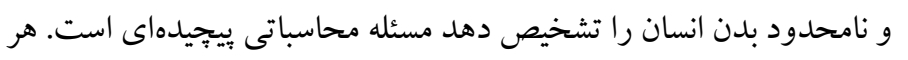
يكك از حركات بدن، جز اطلاعات ورودى دستكاه محسوب مى شود. مؤسسه تحقيقاتى مايكروسافت در كمبريج انخلستان، الكوريتمى به همين منظور ابداع كرده كه زستهاى بدن را تشخيص داده و و بر اساس آنها،

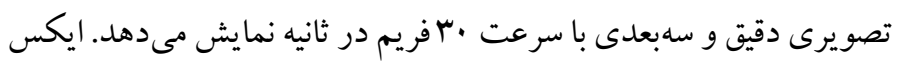


بدون مربى نيز در اين جلسات طراحى شده بود. مدت زمان تمرين مشابه با

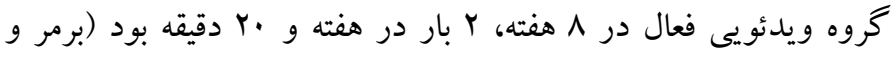

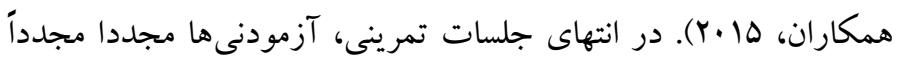

$$
\text { يرسشنامه لذت از فعاليت بدنى مور را تكميل كردند. }
$$

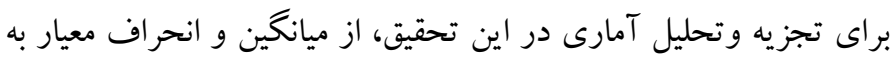

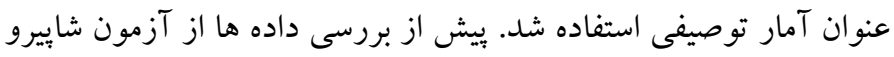

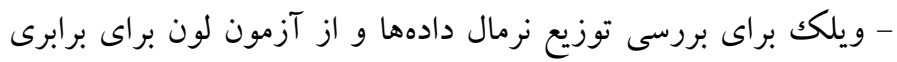

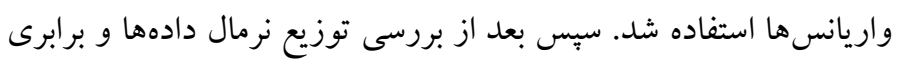

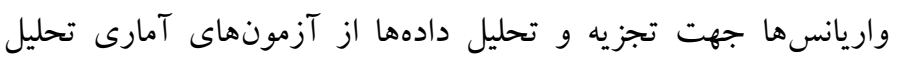
كواريانس به همراه آزمون تعقيبى بنفرونى استفاده شد. كليه تجزيه وتحليل

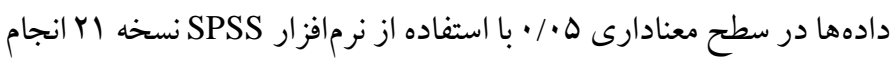

\section{يافتها ها}

شكل ا مربوط به ميانخين و انحراف استاندارد گروه ها در متغير لذت از

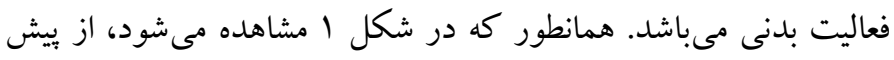

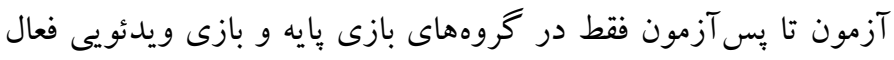

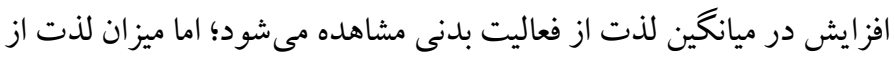

$$
\text { فعاليت بدنى در گروه گُواه كاهش يافته است. }
$$

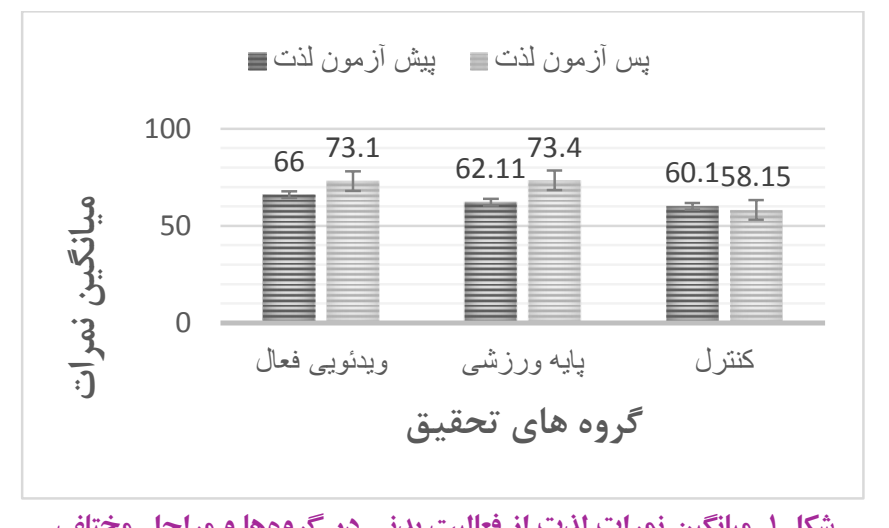

شكل ا. ميانكين نمرات لذت از فعاليت بدنى در كروهها و مر احل مختلف

براى بررسى مقايسه تأثير بازىهاى ويدئويى فعال و بايه ورزشى بر لذت از فعاليت بدنى از آزمون تحليل كواريانس (قبل از تمرين و بعد از تمرين) استفاده شد؛ كه نتايج اين بخش در جدول إنلاصه شده است.
بدست آمد. در كل مىتوان كفت كه اين مقياس به خوبى ميزان لذت از فعاليت بدنى رادر كود كان ارزيابى مى كند.

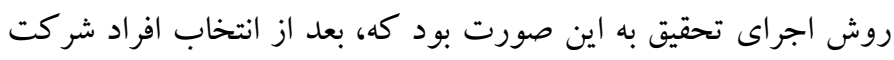

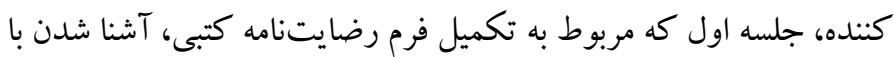
هدف تحقيق بود، انجام شد. شركت كنند كان در اين جلسه درباره شيوه

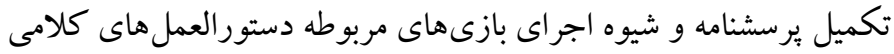

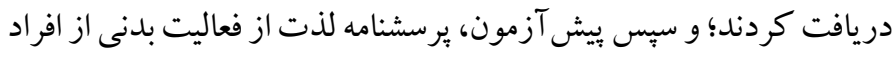

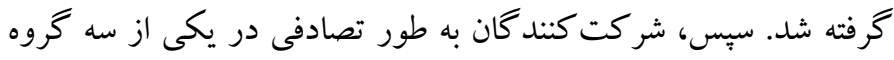
(بازىهاى ويدئويى فعال، بازىهاى بايه ورزشى، گُ اه (ويدئويى غير فعال)

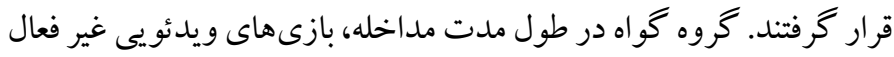

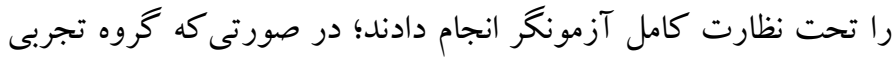

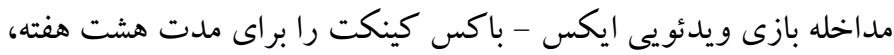
دو بار در هفته و هر جلسه ·r دقيقه (جمعا 19 جلسه) دريافت كرد باكس

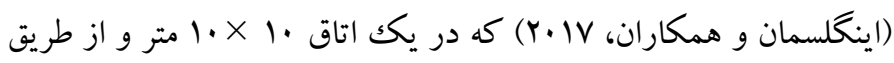

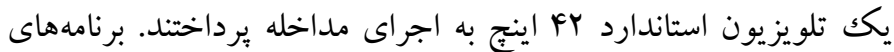

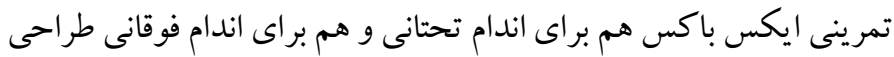

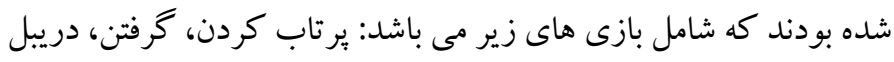

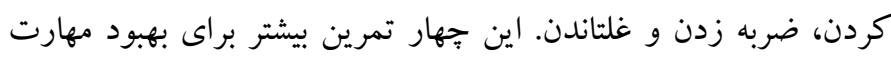

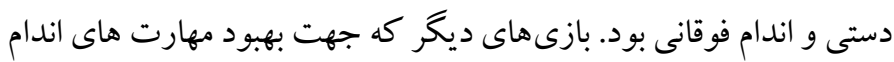

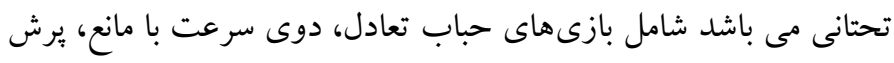

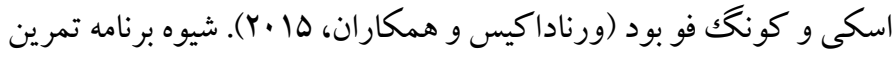

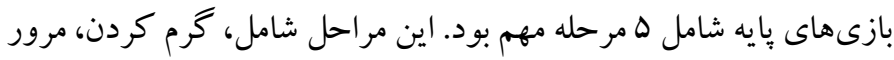

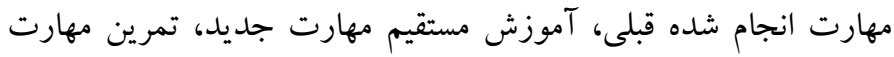

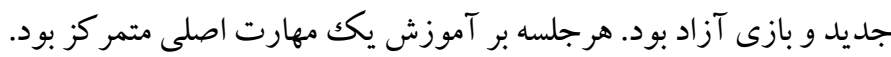

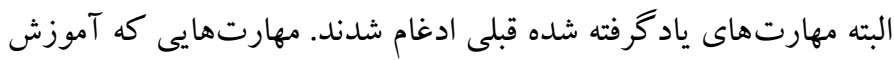
داده شد شامل مهارت جابجايى (دويدن، لى لى كردن، جهيدن و از قبيل

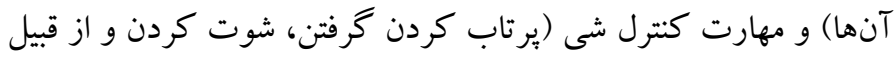

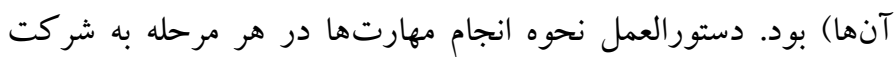

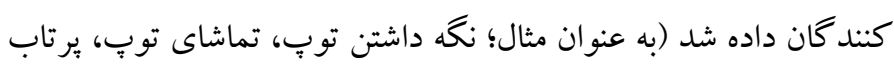

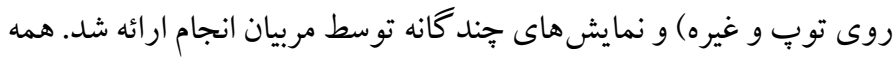

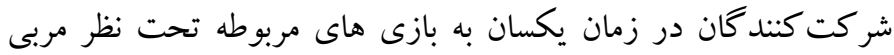

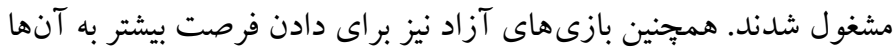




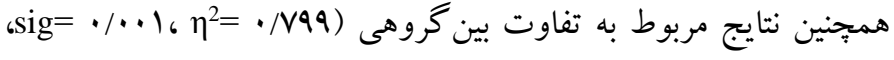

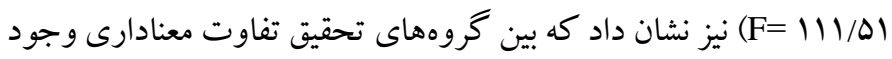

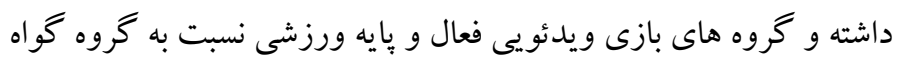

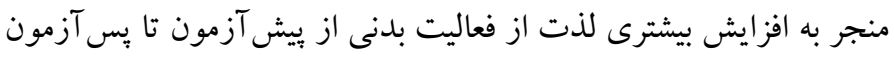

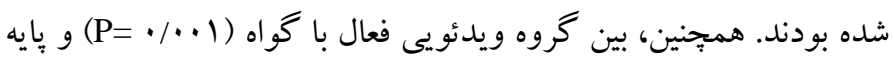

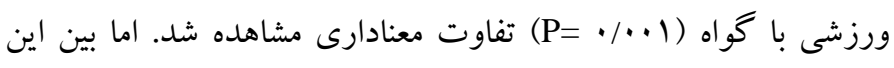

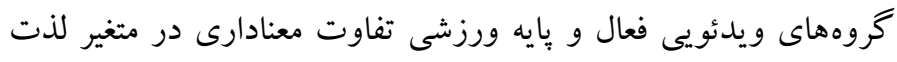

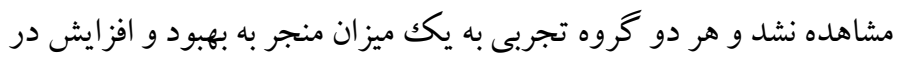

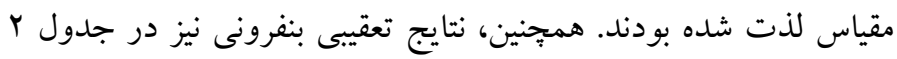
كزارش شده است.
همانطور كه در جدول ا مشاهده مىشود، ما در ابتدا جهت تأييد بيشفرض

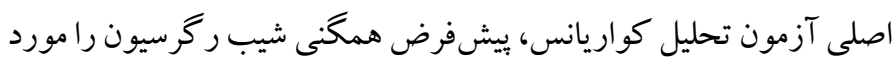

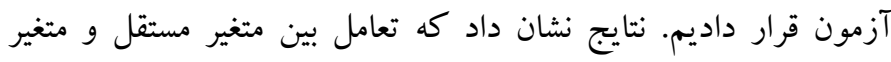

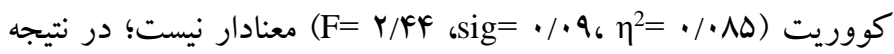
ييش فرض همكنى شيب ركرسيون رعايت شده است.

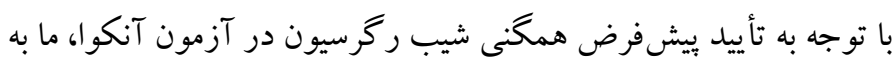

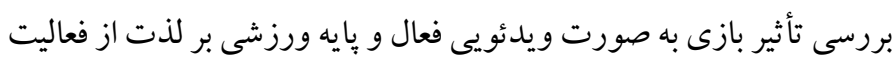

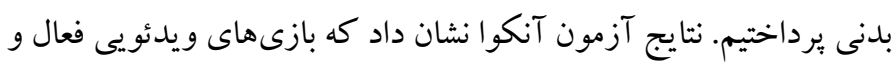

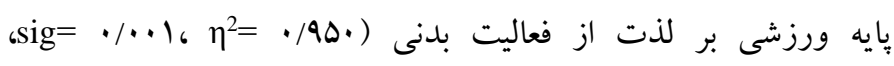
تأثير معنادارى دارد.

جدول ا. نتايج آزمون تحليل كواريانس براى مقياس لذت از فعاليت بدنى

\begin{tabular}{|c|c|c|c|c|c|c|}
\hline مجذور اتا & معنادارى & $\mathrm{F}$ & ميانگين مجذورات & df & مجموع مجذورات & منبع تغييرات \\
\hline$\cdot / \cdot \wedge \Delta$ & .1 .9 & Y/FF & $1 r / 9 r$ & r & $r V / A D$ & 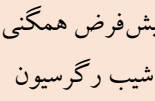 \\
\hline$\cdot / 9 \Delta$ & $* \cdot 1+1$ & $1 \cdot \Delta r / \Lambda q$ & $9 \mid V / 91$ & 1 & $91 V 1 / 91$ & بيش آزمون \\
\hline ./V99 & $* \cdot \cdots 1$ & $111 / \Delta 1$ & $9 \Delta F / V I$ & r & $1 r \cdot q / 4 q$ & كروه \\
\hline$\ldots \ldots .$. & $\ldots \ldots .$. & ........ & $19 / \cdot F$ & $\Delta 9$ & $1.9919 \mathrm{~V}$ & خطا \\
\hline
\end{tabular}

حركتى و روانشناختى وجود دارد؛ لازم است كه بعد روانى نيز مد نظر

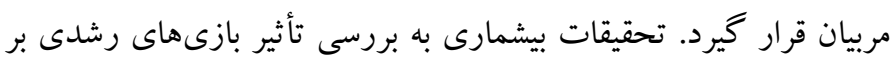

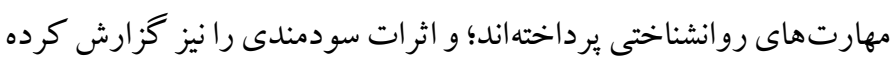

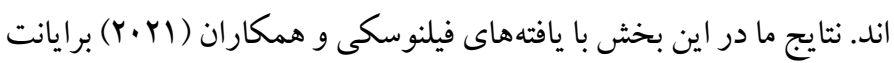

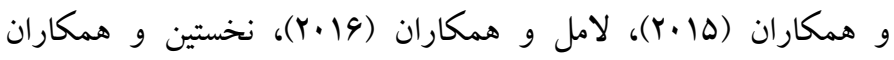

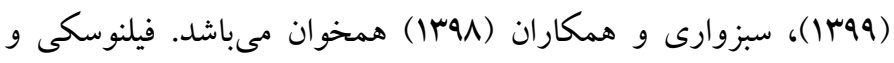
همكاران ( (Y.Y.) در تحقيقى نشان دادند كه شركت در فعاليت بدنى بايه

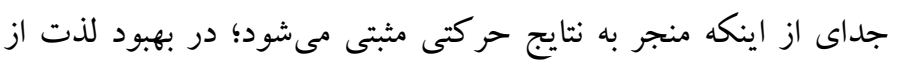

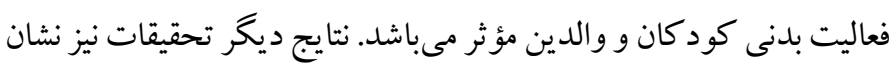

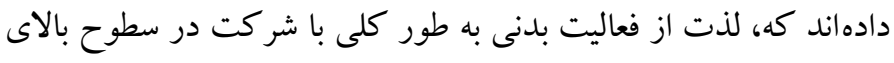

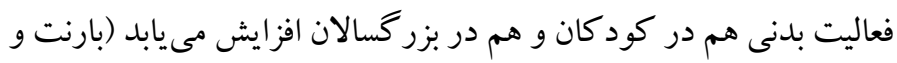

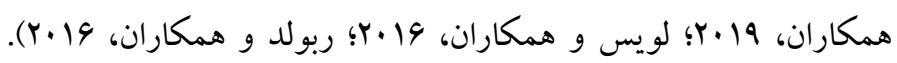
نخستين و همكاران (99 ا1) در تحقيق ديخر نشان داد كه بين گروههاى همان تجربى و كنترل تفاوت معنادارى وجود داشته و بهبود بيشتر در عزتنفس دانش آموزان به نفع گروههاى بازى بومى محلى بود. در تفسير اين موضوع

\begin{tabular}{|c|c|c|c|}
\hline كو اه & بازى يايه ورزشى & بازى ويدئويى فعال & كروه \\
\hline$* \cdot 1 \cdots 1$ & $\cdot / \Delta 9$ & 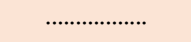 & بازى ويدئويى فعال \\
\hline$* \cdot 1 \cdot 1$ & 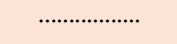 & ..................... & بازى بايه ورزشى \\
\hline . & 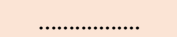 & …................ & كواه \\
\hline
\end{tabular}

\section{بحث و نتيجه تيرى}

هدف از اين تحقيق بررسى مقايسه اثر بازىهاى ويدئويى فعال و يايه

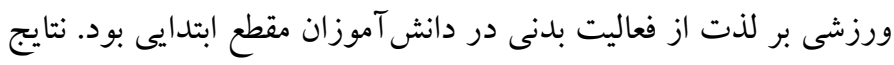

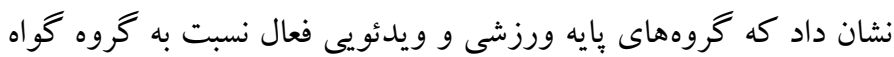
عملكرد بهترى در فاكتور لذت داشتند.

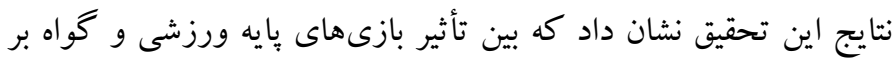

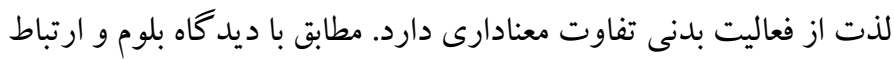

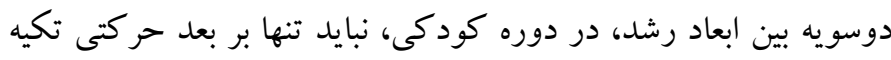

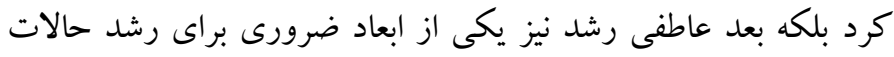

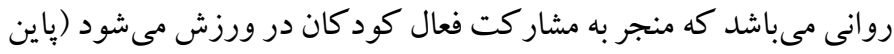
و ايساكس، 1) (Y). بنابراين، به دليل ارتباط بالايى كه بين مهارتهاى 
(آميگدالا) مىرود. اين هسته مسئول كنترل احساسى مثل (حس لذت)

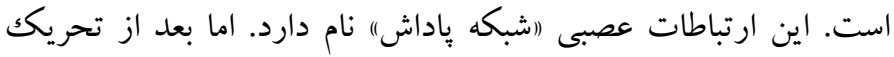
آميخدالا، دويامين به هسته ديخرى در قسمت ميانى مغز به نام استرياتوم

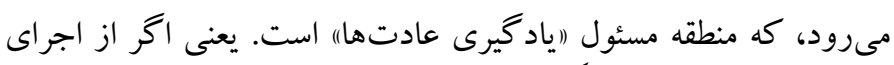

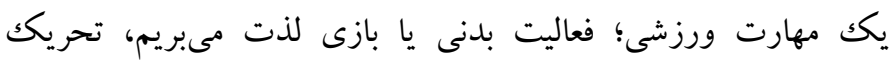

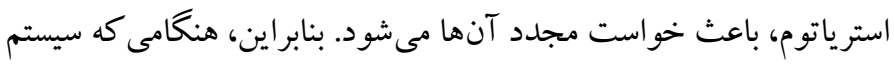
ياداش در ناحيه VTA تحريك مى شود، دويامين توليد شده مى تو اند وارد

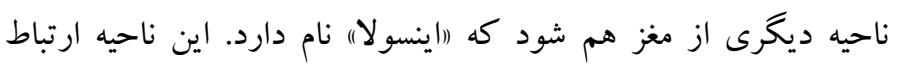

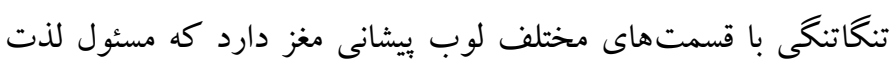

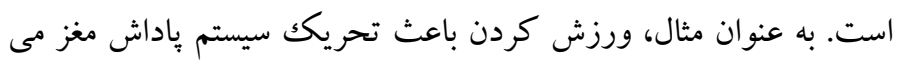

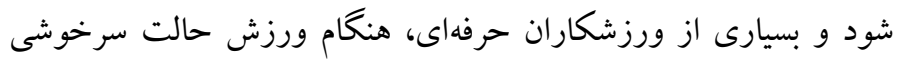

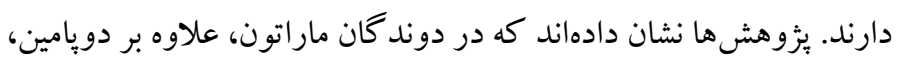

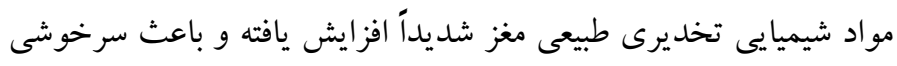
آنها مىشود. در اين حالت ورزشكاران حتى درد را حس نمى كنئد

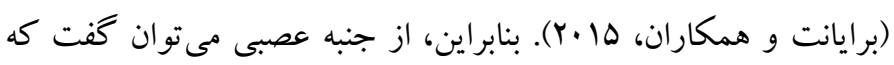

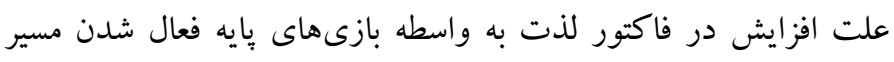

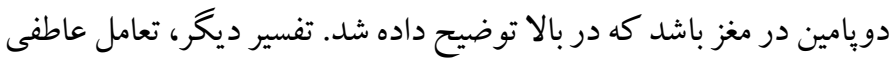

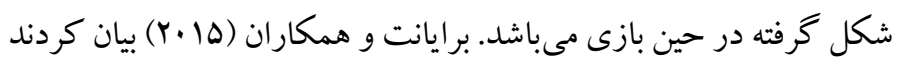

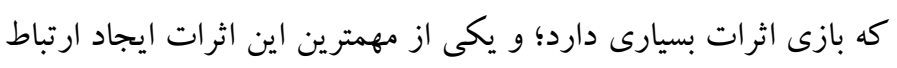
عميق بين حيطههاى رشد حركتى؛ يعنى عاطفى - اجتماعى، شناختى و

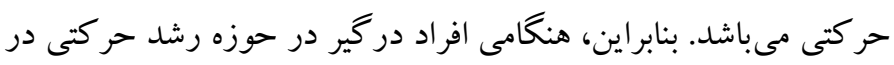
كنار بعد حر كت ساير حيطه هاى ديخر (يعنى عاطفى - اجتماعى، شناختى)

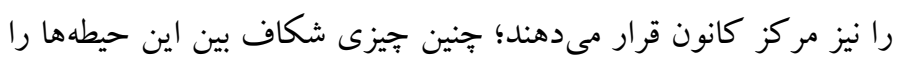
كاهش داده و زمينه شكل گيرى ارتباط عميق بين آنها را فراهم مى كند.

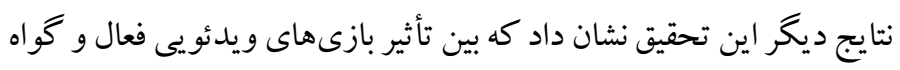

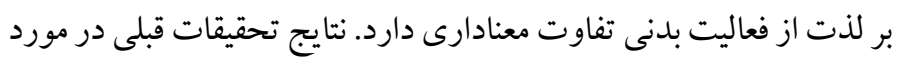

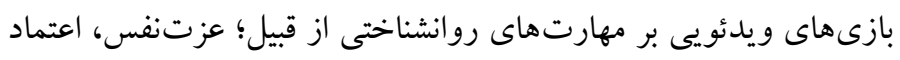

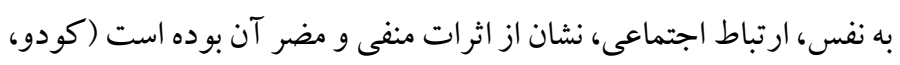

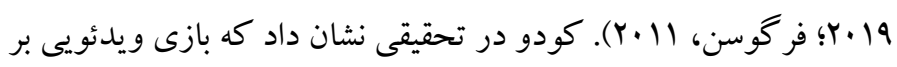

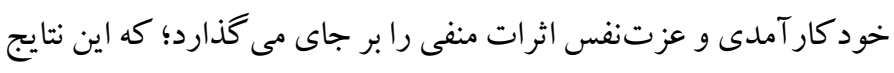

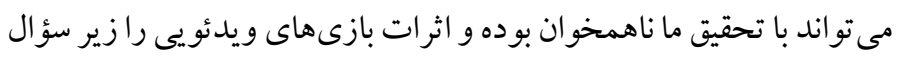

مىتوان به مدل استودن و كفايت حر كتى هارتر اشاره كرد (استودن و

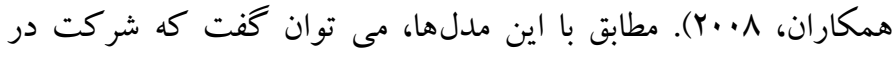

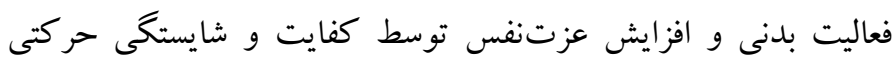

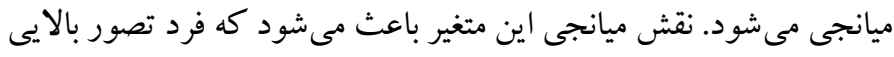

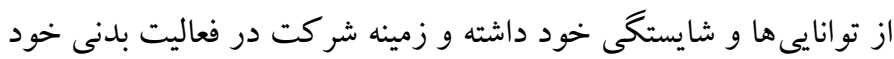

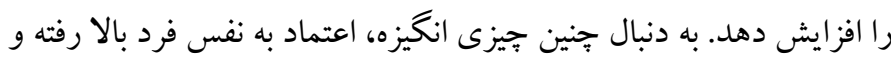

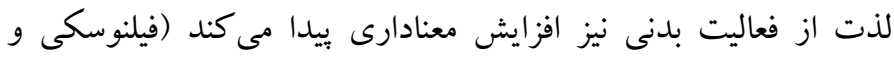

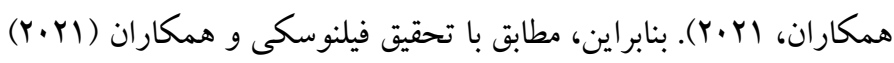

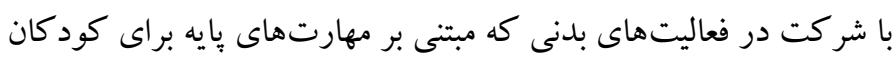

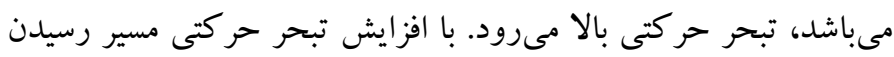
فرد به سطوح بالاى ورزش (تخصصى و قهرمانى) بالا رفته و به دنبال آن

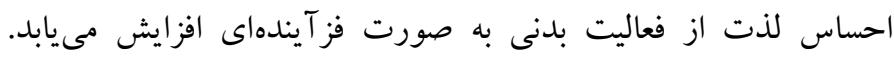

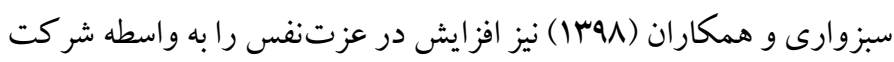

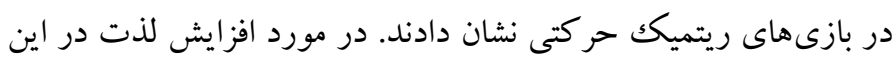
تحقيق به واسطه بازىهاى بايه ورزشى مى توان به دو دليل مهم اشاره كرد.

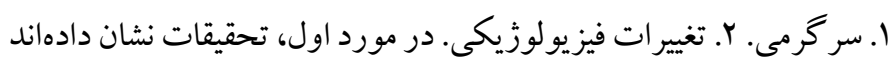

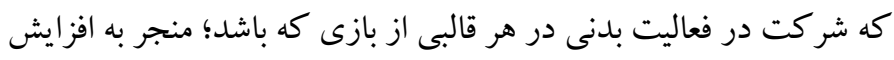

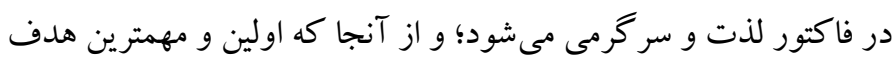

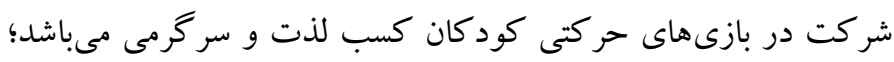
بنابراين طبيعى است كه بازى بر اين فاكتور روانشناختى اثر كذار بار باشد

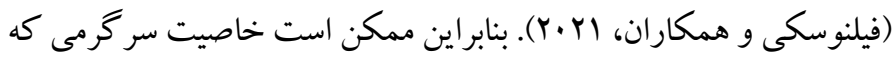
بازىهاى پايه ايجاد مى كنند؛ افراد لذت بالايى را تجربه كرده باشند. در

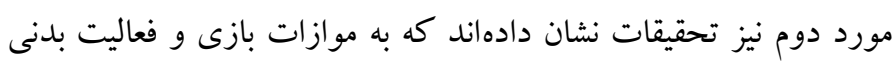
سطح انتقال دهندهاى عصبى به خصوص دوير ديامين و مونامين تغييرات

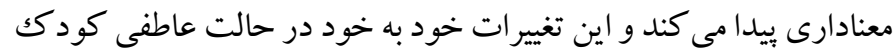

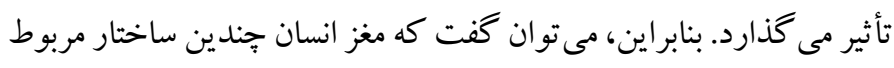

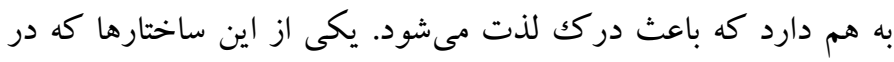

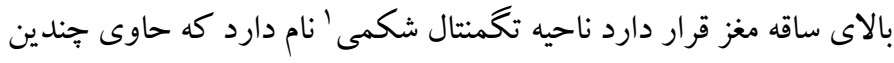

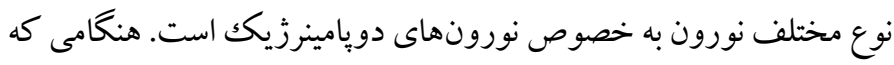
ما به نوعى لذت را تجربه مى كنيم ناحيه VTA توليد مادهاى شيميايى به نام

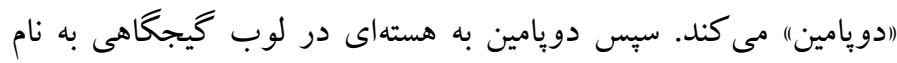

${ }^{1}$. ventral tegmental area 
بيشنهاد كردند كه مشاركت جسمانى فعال از طريق بازىهاى ويدئوى فعال،

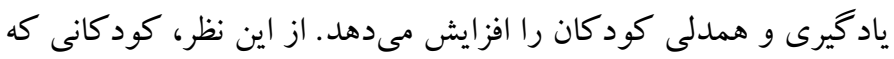

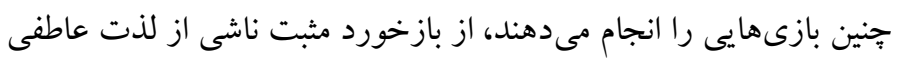

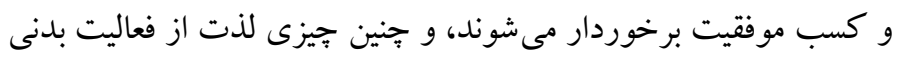
كودكان كودكان را نسبت به تجربيات جديد تقويت كند (بارنت و وروسي

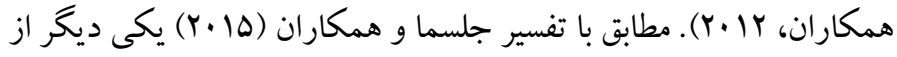

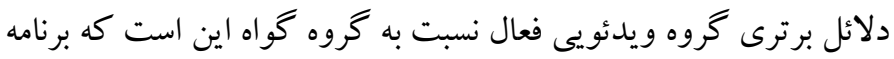
هاى اوليه ممكن است تحريكك ذهنى و جالش بيشترى را براى شركت كترون

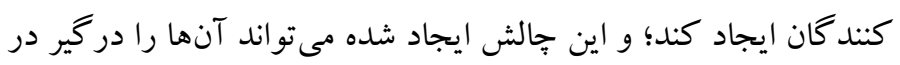
حل مسأله كرده و لذت از مشار كت را در آنها افزايش دهد. آندارده و همكاران ( r.Y.r) در تحقيق مرورى خود تأثير بازىهاى ويدئويى فعال را

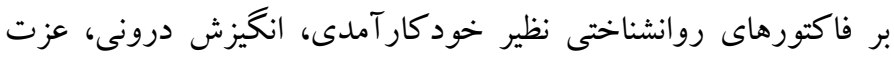

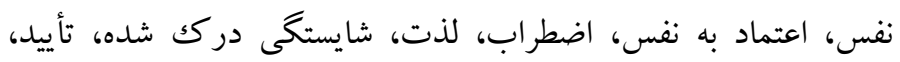

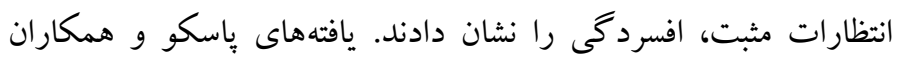

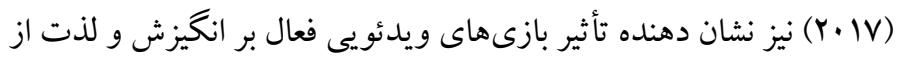

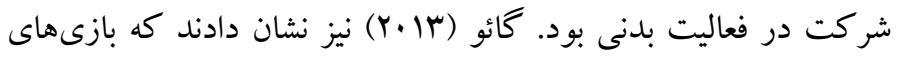

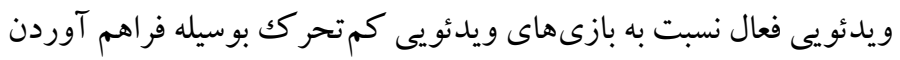

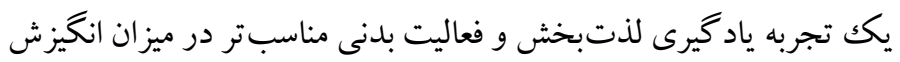

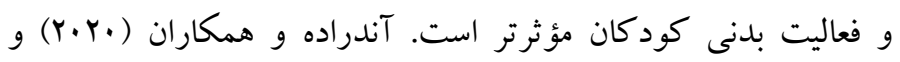
تحقيقات بعدى كه در بالا بعد از آن اشاره كرديم، علت سودمندى بازى

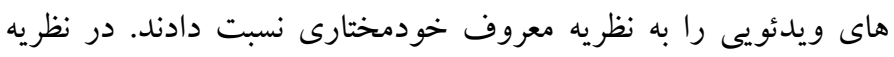
خودمختارى سه نياز اساسى روانى وجود دارد كه شامل؛ خودمختارى، شايستخى و ارتباط است. اعتقاد اين نظريه بر اين است كه اين سه نياز

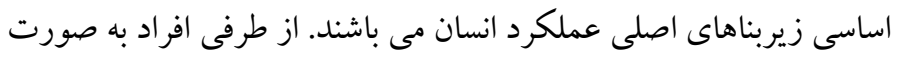
مداوم در محيط در معرض تجربه خودمختارى، شايستخى و ارتباط هستند.

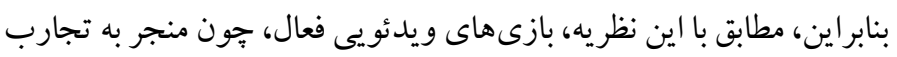

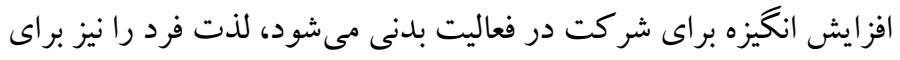

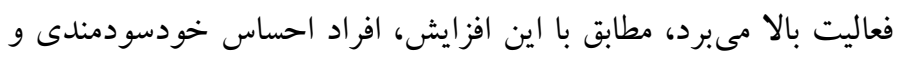
رضايت از عملكرد خود را بالا مىبرند و در نتيجه احساس استقلال و وردائ خودمختارى در آنها يرورش مىيابد. در تفسير ديخر شيهان و كاتز

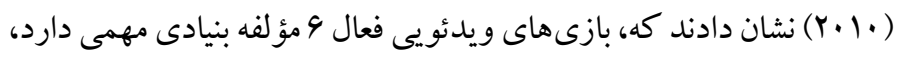
كه منجر به افزايش لذت براى شركت در فعاليت بدنى كود كان به صورت
ببرد. اما؛ مىتوان گفت كه علت ناهمخوانى عدم به كارگيرى شيوه ويدئويى به صورت فعال در تحقيقات قبلى بوده است. زيرا اين شيوه

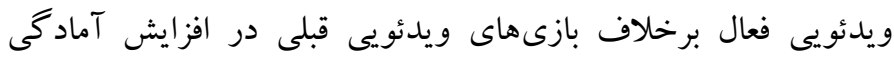

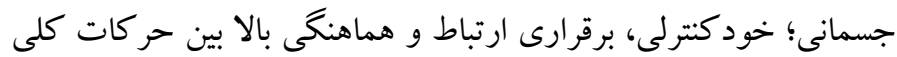

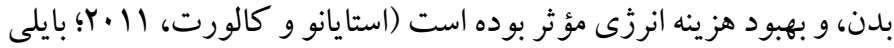
و مكك اينيس، (Y) (Y). نتايج ما در اين تحقيق با يافتهاى اسميت اينگلسمان

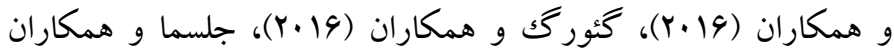

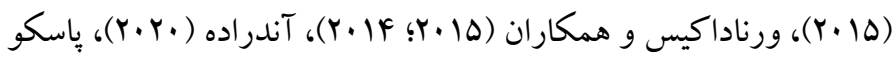

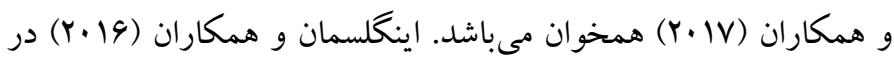
تحقيقى نشان دادند كه بازىهاى ويدئويى فعال منجر به افزايش مقياس

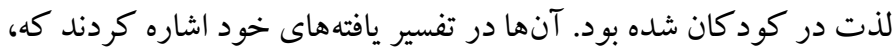

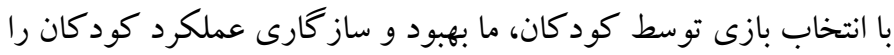
تسهيل كرديم، زيرا با دادن حق انتخاب در حين يا قبل از تمرين، ياد گئيرى

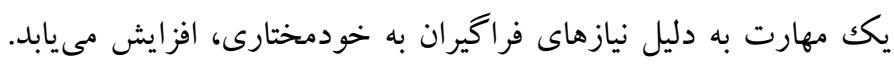
بنابراين، كودكان با داشتن حق انتخاب براى بازى در حين بازىهاى

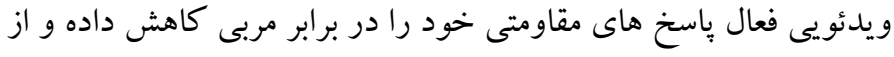

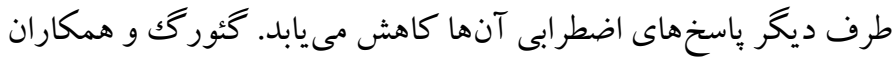

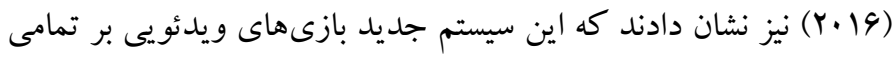

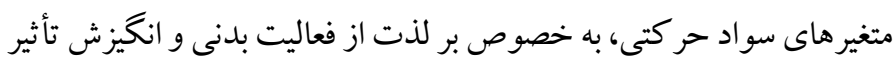

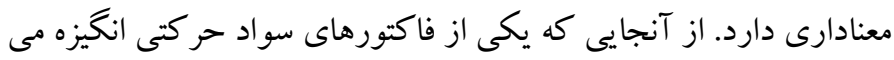

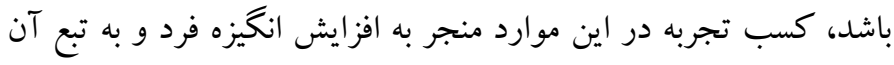

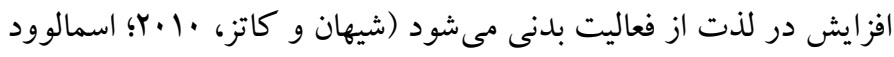

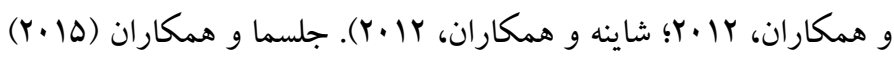
نيز نشان دادند كه كه بازىهاى ويدئويى فعال از طريق افزايش توانايى

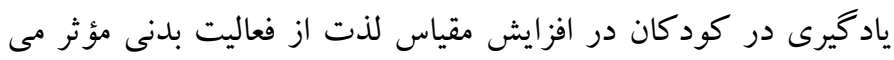
باشند. ورناداكيس و همكاران (ها ·r) در تحقيقى نشان دادند كه بازىهاى

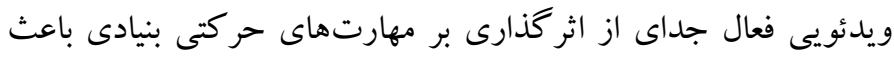

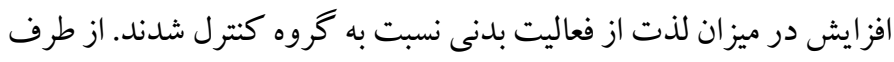

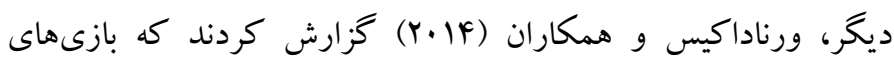
تفريحى مانند Xbox Kinect ممكن است براى كود كان انخيزه ايجاد كند

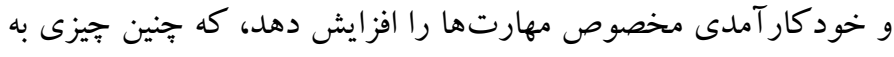
كسب مهارت و كمكك كند. علاوه بر اين، بارنت و همكاران (Y. (Y) 
بخش مهم يافتهاى ما نشان داد كه بين گروههاى ويدئويى فعال و بايه ورزشى بر لذت از فعاليت بدنى تفاوتى وجود نداشته و هر دو به يكك نسبت

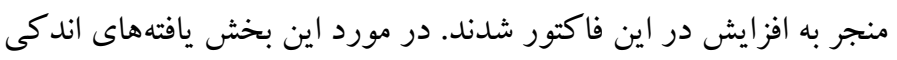

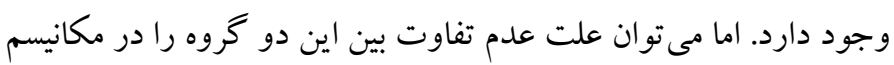

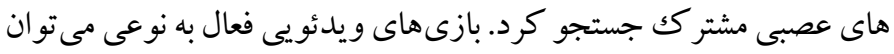
آن را در زمره ياديرى از طريق مشاهده ذكر كرد. تحقيقات حوزه

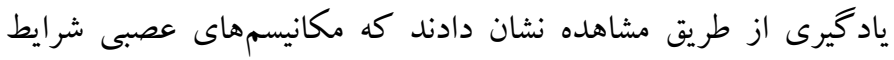
مشاهده و بازى در شر ايط واقعى (بايه ورزشى) مشتر كك مى باشد (ريمال و

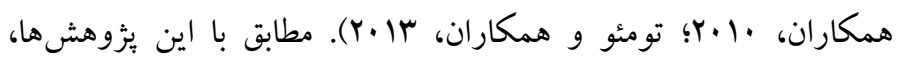
يُزوهشكران با توجه به مطالعات تصويربردارى عصبى، يك شبكه مشاهده

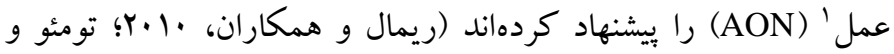

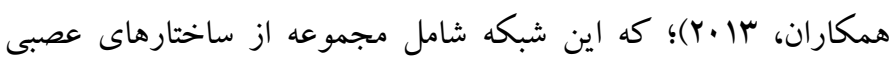
(شامل قشر حركتى اوليه و بيش حركتى، لوب آهيانهاى تحتانى، شيار كيجكاهى فوقانى، ناحيه مكمل حر كتى، شكنج كمربندى و مخجٍه) است

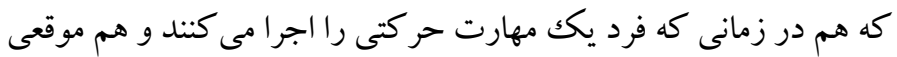

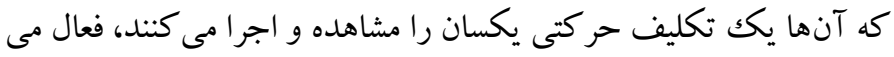

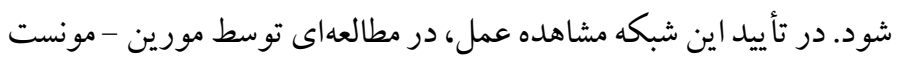

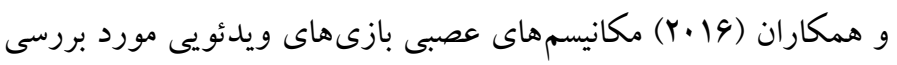
قرار گرفت. آنها در تحقيق خود نشان دادند كه علت برترى بازى ويدئويى باني نسبت به كنترل تحريك يذيرى بيشتر ناحيه حركتى اوليه مىباشد. آنها

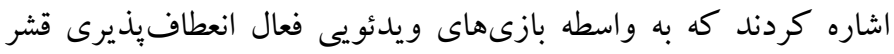

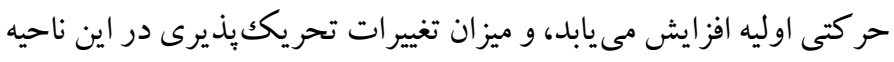

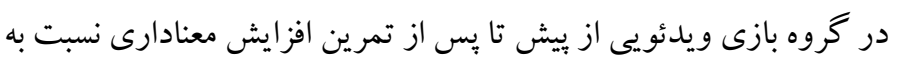

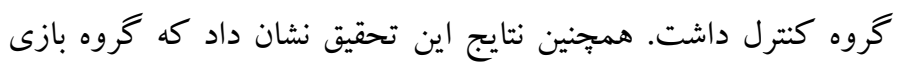

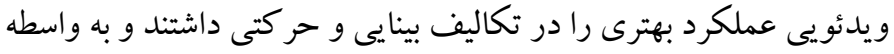
اين عملكرد بهتر در اين بازىها، تحريك يذيرى بيشترى را نيز در قشر

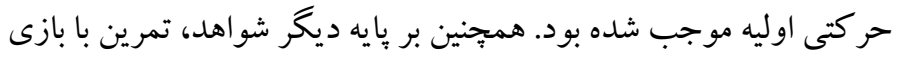

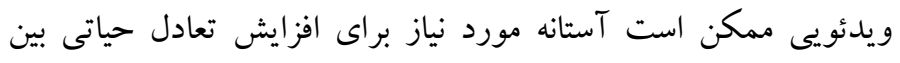
مكانيسمهاى بازدارى و مهارى را كه زمينهساز افزايش انعطافيذيرى قشرى را در تكاليف بينايى حر كتى جديد كاهش دهد (مولر داهلهوس و

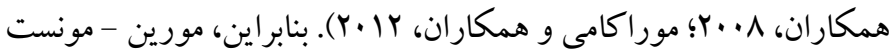

درونى مىشود: كنترل، جالش، كنجكاوى، خلاقيت، بازخورد مداوم و رقابت. مؤلفه اول، به مفهوم خود كنترلى اشاره دارد. در بازىهاى ويدئئوسيى

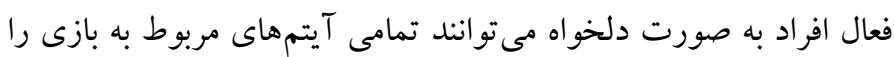
تحت كنترل خود قرار دهند و اين تجربه خودتنظيمى فرد را از تو انايىهاى خود آكاه كرده و ذاتا جنبه لذتبخشى دارد. مولفه دوم، به مفهوم دركير شدن فعال فرد در فر آيند حل مسأله اشاره دارد. در اين مؤلفه فرد هنكام دهام بازىهاى ويدئوى فعال با موانع و مشكلاتى روبرو مى شود و در صورت

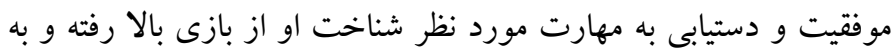

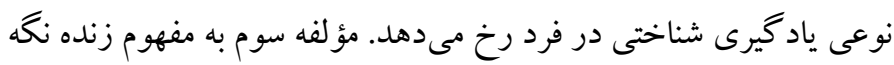

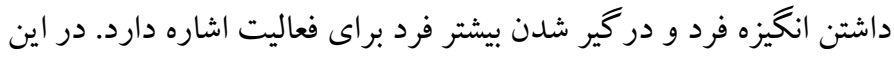

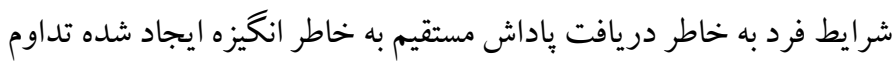

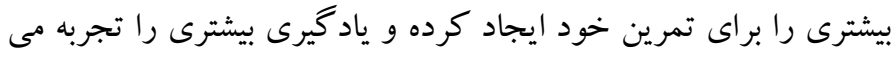

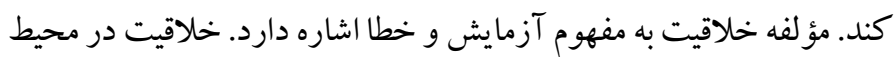
مجازى فرد را به آزمايش و مقابله با فر آيند حل مسأله به مبارزه مى طعلبد. بنابراين، فرد در مواجهه شده با آزمايش و خطاهاى مختلف به خوبى

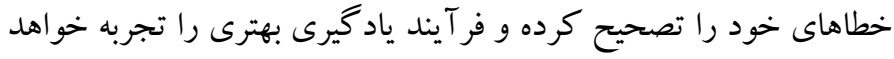

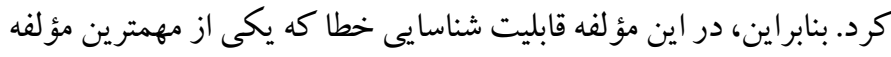

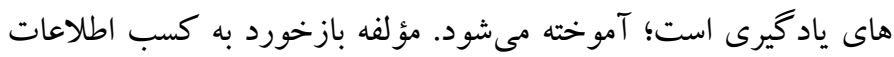
دريافت شده اشاره دارد. در طول بازىهاى ويدئويى اطلاعات دقيق اما مصنوعى در مورد بيشرفت فرد در اختيار او قرار مى گيرد. دقيقا مثل قابليت شناسايى خطاى اشاره شده در بالا، بازخورد نيز مورد تحقيقات بسيارى در

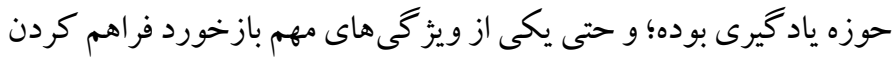

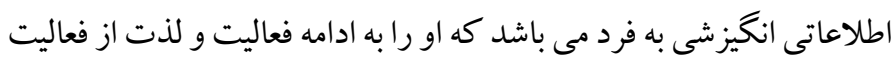
وادار مى كند. و اينكه مؤلفه آخر يعنى رقابت؛ شر ايطى را براى فرد فر فراهم

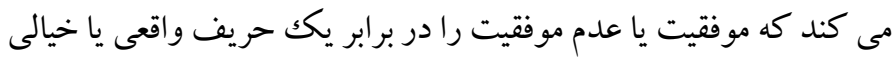
تجربه كند. جداى از اين مطالعات اخير به تازگى، تقاضاى توجه، فرصت

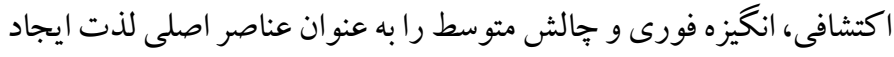

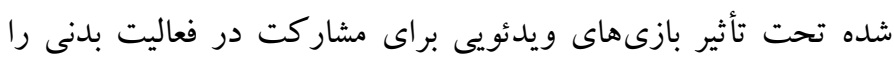

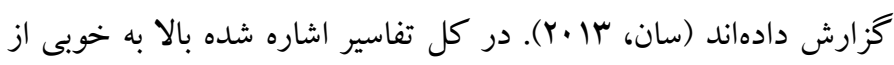
يافتهاى ما در اين بخش حمايت مى كند.

${ }^{1}$. action observation network 
در كل نتايج اين تحقيق نشان داد كه بازىهاى ويدئويى فعال و يايه ورزشى بر لذت از فعاليت بدنى دانش آموزان تأثير معنادارى دارند. همجينين در مورد تفاوتها نتايج اين تحقيق نشان داد كه بين اين دو شيوه بازى تفاوتى وجود ندارد و هر دو به يكك ميزان منجر به افزايش در لذت از فعاليت بدنى شدند. بنابراين مىتوان از رويكرد بازىهاى ويدئويى فعال در شرايطى كه زمينه بازى در حالت واقعى فراهم نيست به صورت يكك شيوه جايكزين و ونائ مؤثر استفاده كرد.

ملاحضات اخلاقى

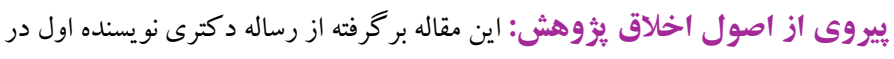

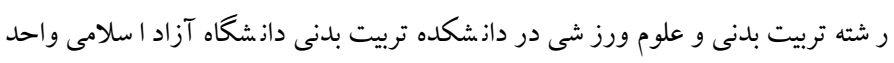

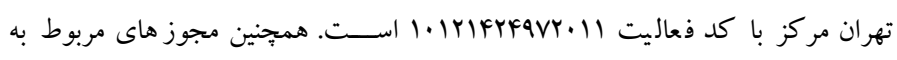

يُوهش در جامعه آمارى از طرف آموزش و يرورش شهر اهواز صادر شده است. حامى مالى: اين يزوهش در قالب رساله دكترى و بدون حمايت مالى مىباشد. نقش هر يكك از نويسند كان: نويسنده اول محقق اصلى اين بثوهش است. نويسنده دوم استاد راهنما، و نويسنده سوم استاد مشاور اين رساله مىباشد. تضاد منافع: هيج تضاد منافعى در ارتباط با اين يزوهش وجود ندارد. ت شكر و قدردانى: بدين وسيله از اسـاتيد راهنما و مشـاور اين تحقيق و نيز كود كان و والدين شر كت كننده كه در انجام اين يثزوهش يارى نمودند تشكر و قدردانى مى خردد.
و همكاران (Y (Y) نشان داد كه بازى از طريق مشاهده ويدئوى مثل بازى در شرايط واقعى (يايه ورزشى) يكك مكانيسم عصبى مشتركك كه قشر حر كتى اوليه مىباشد را فعال مى كنند. همجِنين مطابق با تحقيق سبزوارى و همكاران (IrqV) بازى و ورزش، تجربيات عملى و انواع فعاليتهاى جالشبرانگيز منبع اصلى يادگيرى هستند؛ بازى و ورزش براى بهبود كاركردهاى مغزى بسيار حائز اهميت است؛ فعاليتهايى جون دويدن، يريدن، جهيدن، شنا كردن، كه جزو مهارتهاى يايه ورزشى مىباشند سبب تقويت عقدههاى قاعدهاى و مخجهه و جسم بينهاى مى شود؛ ورزش و فعاليت بدنى اكسيزن زيادى به مغز مىرساند و باعث افزايش ارتباط بين نرونى مىشود كه ياد گيرى را ارتقا و تقويت مى كند (قربانى و قيصرى، و. IV تحت شرايط بازى واقعى اشاره شده است كه در شرايط يازى ويدئويى نيز اين فعاليت توسط محققان گزارش شده است (آندريئو كس و يروتئو، 19 (Y). بنابر اين، مى توان كفت كه علت عدم تفاوت در كروههاى يايه و ويدئويى همين مكانيسم عصبى مشتركى باشد كه در بالا به آن اشاره شده است. با اين وجود، براى رسيدن به نتايج قطعى در مورد اين عدم تفاوت تحقيقات بيشترى بايد صورت كيرد تا به تعميم نتايج كمكك شايانى كند. 


\section{References}

Amin Nasab, V., Banijamali, S. A., \& Hatami, H. (2019). The effectiveness of cognitive-motor learning training on social adjustment, motor skills and ADHD symptoms reduce in preschool children aged 5 and 6 years. Journal of psychologicalscience, 17(72), 883-892. [Link]

Andrade, A., Correia, C. K., \& Coimbra, D. R. (2020). The psychological effects of exergames for children and adolescents with obesity: a systematic review and meta-analysis. Cyberpsychology, Behavior, and Social Networking, 22(11), 724-735. [Link]

Andrieux M., \& Proteau L. (2016). Observational Learning: Tell Beginners What They Are about to Watch and They Will Learn Better. Frontiers in Psychology. (7): 1-9. [Link]

Bailey BW, McInnis K. (2011) Energy cost of exergaming: a comparison of the energy cost of 6 forms of exergaming. Arch of ped \& adoles med. 4(7):597-602. [Link]

Barnett, E. Y., Ridker, P. M., Okechukwu, C. A., \& Gortmaker, S. L. (2019). Integrating children's physical activity enjoyment into public health dialogue (United States). Health Promotion International, 34(1), 144-153. [Link]

Bremer E, Balogh R, Lloyd M. (2015). Effectiveness of a fundamental motor skill intervention for 4-year-old children with autism spectrum disorder: A pilot study. Autism. 19(8):980-91. [Link]

Bremer E, Lloyd M. (2016). School-based fundamentalmotor-skill intervention for children with autismlike characteristics: an exploratory study. Adapt Phys Activ Q. 33(1):66-88. [Link]

Bryant, E., Duncan, M., Birch, S., \& James, R. (2015). The effect of a fundamental movement skill intervention on physical skill self-efficacy and motor skill competence in overweight and obese children. Appetite, (87), 385. [Link]

Cebolla AA, ' lvarez-Pitti JC, Provinciale JG. (2015). Alternative options for prescribing physical activity among obese children and adolescents: brisk walking supported by an exergaming platform. Nut Hospitalaria. 31(2): 841- 848. [Link]

Costello K, Warne J. (2020). A four-week fundamental motor skill intervention improves motor skills in eight to 10 -year-old Irish primary school children.
Cogent Soc Sci. 6(1):1724065. [Link]

Courtney, J. B., Moss, H. E., Butki, B. D., \& Li, K. (2019). Parent support, perceptions, and child attributes affect child activity. American Journal of Health Behavior, 43(2), 311-325. [Link]

Cudo, A., Kopiś, N., \& Zabielska-Mendyk, E. (2019). Personal distress as a mediator between self-esteem, self-efficacy, loneliness and problematic video gaming in female and male emerging adult gamers. Plos One, 14(12), e0226213. [Link]

Ferguson CJ, Coulson M, Barnett J. A. (2011). Metaanalysis of pathological gaming prevalence and comorbidity with mental health, academic and social problems. Journal of psychiatric research. 45 (12):1573-8. [Link]

Filanowski, P. M., Iannotti, R. J., Camhi, S. M., Whiteley, J. A., \& Milliken, L. A. (2021). Physical activity and enjoyment in parent-child dyads during shared physical activity. Research quarterly for exercise and sport, 92(1), 127-136. [Link]

Gao Z, Podlog L, Huang C. (2013). Associations among children's situational motivation, physical activity participation, and enjoyment in an active dance video game. Journal of Sport and Health Science 2:122-128. [Link]

George AM, Rohr LE, Byrne J. (2016). Impact of Nintendo Wii games on physical literacy in children: Motor skills, physical fitness, activity behaviors, and knowledge. Sports. 4(1):3. [Link]

Ghari B, Mohammadzadeh H, Dehghanizade J. (2021). A Comparison of Game Based and Traditional Instructional Approaches: A Study of Physical Activity, Self-Determined Motivation and Enjoyment. Development \& Motor Learning. 1: 111-127. (Persian). [Link]

Ghorbani Qahfarhi, L, Qaisari, N. (2017). The effect of morning exercise on the academic achievement of first grade, second and third year elementary school students. JARSM. 6(21): 97-106. [Link]

Hashemi, A., Sheikh, M., Homanian, D., \& Bagherzadeh, F. (2019). The effect of Wii Fit exercises on clumsiness and quality of life in children with developmental coordination disorder. 74: 143-152. [Link]

Jekauc, D., Voelkle, M., Wagner, M. O., Mewes, N., \& Woll, A. (2013). Reliability, validity, and 
measurement invariance of the German version of the physical activity enjoyment scale. Journal of pediatric psychology, 38(1), 104-115. [Link]

Jelsma, D., Geuze, R. H., Mombarg, R., \& SmitsEngelsman, B. C. (2014). The impact of Wii Fit intervention on dynamic balance control in children with probable Developmental Coordination Disorder and balance problems. Human movement science, 33, 404-418. [Link]

Lämmle, C., Kobel, S., Wartha, O., Wirt, T., \& Steinacker, J. M. (2016). Intervention effects of a school-based health promotion program on children's motor skills. Journal of Public Health, 24(3), 185-192. [Link]

Lee J, Zhang T, Chu TL, Gu X, Zhu P. (2020). Effects of a fundamental motor skill-based afterschool program on children's physical and cognitive health outcomes. Int $\mathrm{j}$ of env res pub health. 17(3):733. [Link]

Lee S, Kim W, Park T, et al. (2017). The psychological effects of playing exergames: a systematic review. Cyberpsychology, Behavior, and Social Networking. 20:513-532. [Link]

Lewis, B. A., Williams, D. M., Frayeh, A., \& Marcus, B. H. (2016). Self-efficacy versus perceived enjoyment as predictors of physical activity behaviour. Psychology \& Health, 31 (4), 456-469. [Link]

Mohammadzadeh, M., Sheikh, M., Houminiyan, D., Bagherzadeh, F., \& Kazemnejad, A. Evaluation of psychometric properties of perceived physical literacy instrument (ppli) in Iranian adolescents. Journal of psychologicalscience, 843-850. [Link]

Mokaberian. M, Kashani. V, Sedighifaroji. F. (2018). Validation of the Persian version of Physical Activity Enjoyment Scale in Children. Motor Behavior. 9 (30): 17-36. (Persian). [Link]

Morin-Moncet, O., Therrien-Blanchet, J. M., Ferland, M. C., Théoret, H., \& West, G. L. (2016). Action video game playing is reflected in enhanced visuomotor performance and increased corticospinal excitability. PLoS one, 11(12), e0169013. [Link]

Müller-Dahlhaus, J. F. M., Orekhov, Y., Liu, Y., \& Ziemann, U. (2008). Interindividual variability and age-dependency of motor cortical plasticity induced by paired associative stimulation. Experimental brain research, 187(3), 467-475. [Link]

Murakami, T., Müller-Dahlhaus, F., Lu, M. K., \& Ziemann, U. (2012). Homeostatic metaplasticity of corticospinal excitatory and intracortical inhibitory neural circuits in human motor cortex. The Journal of physiology, 590(22), 5765-5781. [Link]

Nokhostin Abed Sham Asbi F, Mohammadi Orangi B, Yaali R, Ghadiri F. (2020). Compare the effects of Indigenous-Local play and selective motor interventions on the Self-esteem of obese girls in pre-school ages in Tehran. Journal of motor and behavioral sciences. 3(1):103-12. (Persian). [Link]

Pasco D, Roure C, Kermarrec G, Pope Z, GAO Z (2017). The effects of a bike active video game on players' physical activity and motivation. Journal of Sport and Health Science 6: 25-32. [Link]

Rymal A.M., Martini R., \& Ste-Marie D.M. (2010). Selfregulatory processes employed during selfmodeling: a qualitative analysis. Sport Psychology. (24): 1-15. [Link]

Sabzevari H, Arsham S, Parvinpor Sh. (2019). Effect of rhythmic motor games on Motor Proficiency, educational achievement and self-esteem in children with developmentally coordination disorder. Razi J Med Sci. 26(7):66-77. [Link]

Shayne, R.K.; Fogel, V.A.; Miltenberger, R.G.; SKochler, S. (2012). The effects of exergaming on physical activity in the third grade physical education class. J. Appl. Behav. Anal. 45, 211-215. [Link]

Sheehan, D.; Katz, L. (2010). Using interactive fitness and exergames to develop physical literacy. Phys. Health Educ. J. 76, 12-19. [Link]

Smallwood, S.R.; Morris, M.M.; Fallows, S.J.; Buckley, J.P. (2012). Physiologic responses and energy expenditure of Kinect active video game play in schoolchildren. Arch. Pediat. Adol. Med. 166, 1005-1009. [Link]

Smits-Engelsman BC, Jelsma LD, Ferguson GD. (2017). The effect of exergames on functional strength, anaerobic fitness, balance and agility in children with and without motor coordination difficulties living in low-income communities. Hum mov sci. 55:327-37. [Link]

Staiano AE, Calvert SL. (2011). Exergames for physical education courses: physical, social, and cognitive benefits. Child Devel Persp. 5:93-98. [Link] 
Stodden, D. F., Goodway, J. D., Langendorfer, S. J., Roberton, M. A., Rudisill, M. E., Garcia, C., \& Garcia, L. E. (2008). A developmental perspective on the role of motor skill competence in physical activity: An emergent relationship. Quest, 60(2), 290-306. [Link]

Sun H. (2013). Impact of exergames on physical activity and motivation in elementary school students: a follow-up study. Journal of Sport and Health Science. 2:138-145. [Link]

Sween J, Wallington SF, Sheppard V, et al. (2014). The role of exergaming in improving physical activity: a review. J of Phy Act and Health. 11:864-870. [Link]

Tomeo E., Cesari P., Aglioti S.M., \& Urgesi C. (2013). Fooling the kickers but not the goalkeepers: behavioral and neurophysiological correlates of fake action detection in soccer. Cerebral Cortex. (23): 2765-2778. [Link]

Vernadakis N, Papastergiou M, Zetou E, Antoniou P. (2015). The impact of an exergame-based intervention on children's fundamental motor skills. Comput Educ. 83:90-102. [Link]

Vernadakis, N., Derri, V., Tsitskari, E., \& Antoniou, P. (2014). The effect of Xbox Kinect intervention on balance ability for previous injured young competitive male athletes: a preliminary study. Physical Therapy in Sport, 15(3), 148e155. [Link]

Weiss, M. R., Kimmel, L. A., \& Smith, A. L. (2001). Determinants of sport commitment among junior tennis players: Enjoyment as a mediating variable. Pediatric Exercise Science, 13, 131-144. [Link] 